\title{
Genetic alteration of histone lysine methyltransferases and their significance in renal cell carcinoma
}

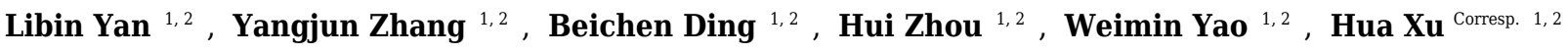 \\ 1 Urology, Tongji Hospital,Tongji Medical College, Huazhong University of Science Technology, Wuhan, Hubei, China \\ 2 Institute of Urology of Hubei Province, Wuhan, China \\ Corresponding Author: Hua Xu \\ Email address: xuhuawhu@163.com
}

Background. Histone lysine methyltransferases (HMTs), a category of enzymes, play essential roles in regulating transcription, cellular differentiation, and chromatin construction. The genomic landscape and clinical significance of HMTs in renal cell carcinoma (RCC) remain uncovered.

Methods. We conducted an integrative analysis of 50 HMTs in renal cell carcinoma and discovered the internal relations among copy number alterations (CNA), expressive abundance, mutations and clinical outcome.

Results. We confirmed 12 HMTs with the highest frequency of genetic alterations, including 7 HMTs with high-level amplification, 2 HMTs with somatic mutation and 3 HMTs with putative homozygous deletion. Patterns of copy number and expression varied among different subtypes of RCC, including clear cell renal cell carcinoma (ccRCC), papillary cell carcinoma ( $p R C C)$ and chromophobe renal carcinoma (chRCC). Kaplan-Meier survival analysis and multivariate analysis identified that CNA or mRNA expression in some HMTs were significantly associated with shorter overall patient surviva I. Systematic analysis identified six HMTs (ASH1L, PRDM6, NSD1, EZH2, WHSC1L1, SETD2) which were dysregulated by genetic alterations as candidate therapeutic targets.

Discussion. In summary, our findings strongly evidenced that genetic alteration of HMTs may play an important role in generation and development of renal cell carcinoma, which lays a solid foundation for the mechanism for further research in the future . 
1 Genetic alteration of histone lysine methyltransferases and their

2

3

4

5

6 1, Urology, Tongji Hospital, Tongji Medical College, Huazhong University of Science

7 Technology, Wuhan, Hubei, China;

8 2, Institute of Urology of Hubei Province, Wuhan, China.

$9{ }^{*}$ corresponding author: Prof. Hua Xu, Urology, Tongji Hospital, Tongji Medical College, significance in renal cell carcinoma

\section{Libin Yan ${ }^{1,2}$, Yangjun Zhang ${ }^{1,2}$, Beichen Ding ${ }^{1,2}$, Hui Zhou ${ }^{1,2}$,} Weimin Yao ${ }^{1,2}$, Hua $\mathrm{Xu}^{1,2^{*}}$

\section{7-836-63454, Email: xuhuawhu@163.com}




\section{Abstract}

17 Background. Histone lysine methyltransferases (HMTs), a category of enzymes, play essential roles in regulating transcription, cellular differentiation, and chromatin construction. The genomic landscape and clinical significance of HMTs in renal cell carcinoma (RCC) remain uncovered.

Methods. We conducted an integrative analysis of 50 HMTs in renal cell carcinoma and discovered the internal relations among copy number alterations (CNA), expressive abundance, mutations and clinical outcome.

Results. We confirmed 12 HMTs with the highest frequency of genetic alterations, including 7 HMTs with high-level amplification, 2 HMTs with somatic mutation and 3 HMTs with putative homozygous deletion. Patterns of copy number and expression varied among different subtypes of RCC, including clear cell renal cell carcinoma (ccRCC), papillary cell carcinoma (pRCC) and chromophobe renal carcinoma (chRCC). Kaplan-Meier survival analysis and multivariate analysis identified that CNA or mRNA expression in some HMTs were significantly associated with shorter overall patient survival. Systematic analysis identified six HMTs (ASH1L, PRDM6, NSD1, EZH2, WHSC1L1, SETD2) which were dysregulated by genetic alterations as candidate therapeutic targets.

Discussion. In summary, our findings strongly evidenced that genetic alteration of HMTs may play an important role in generation and development of renal cell carcinoma, which lays a solid foundation for the mechanism for further research in the future. 
Introduction

Renal cell carcinoma (RCC) accounts for nearly 5\% of adult malignancies with about 63,920 new cases and 13,860 deaths in the United States (Siegel et al., 2014). RCC is histologically classified into several subtypes, including clear cell renal cell carcinoma (ccRCC), papillary cell carcinoma (pRCC) and chromophobe renal carcinoma (chRCC), among which ccRCC is the most common subtype and accounts for approximately $70-80 \%$ of all RCC (Yan et al., 2009). In addition to surgical treatment, current targeted therapies have slightly improved overall survival in patients with advanced disease. Histone lysine methyltransferase (HMT) and demethylases control the process of histone lysine methylation, which is a crucial part of epigenetics (Greer \& Shi, 2012; Albert \& Helin, 2010). To date, over 50 human HMTs have been revealed (Herz et al., 2013). In the structure, the HMTs are a group of various proteins, which are typically categorized by two functional enzyme families, the SET-domain-containing methyltransferase and DOT1L lysine methyltransferase (Albert \& Helin, 2010; Herz et al., 2013) (Table 1). Recent researches have shown that HMT dysregulation leads to uncontrollable histone methylation pathways and contributes to the pathogenesis of many human cancers, including RCC (Niu et al., 2012; Roy et al., 2014; Shen \& Laird, 2013; Vieira-Coimbra et al., 2015; Pires-Luís et al., 2015). Several studies indicated that the methyltransferase gene SETD2 was frequently mutated during epigenetic progress in RCC (Tiedemann et al., 2016). It was also demonstrated that SETD2mutated patients were characterized by loss of function of nucleosome structure, replisome occupancy, replication fork progression and DNA repair by homologous replication (Kanu et al., 2015). Also, EZH2, a histone 3 lysine 27 methyltransferase, proved to be associated with poor 
59

60

prognoses in ccRCC (Wagener et al., 2008a; Wagener et al., 2010). Increasing evidences showed that genetic alterations of several HMTs play crucial roles in oncogenesis (Shen \& Laird, 2013; Roy et al., 2014; Tian et al., 2013). By far, there is no systematic analysis of genomic aberration of HMTs in RCC. Furthermore, the clinical relevance of genetic alterations in each HMT in RCC remains unclear. Our goal, therefore, is to demonstrate the genomic alteration of HMTs in RCC and assess their diagnostic and prognostic potential.

\section{Materials and methods}

\section{Samples with genomic and clinical data}

The DNA copy number, gene expression, mutation, clinicopathological data and overall survival datasets of 882 renal cell carcinoma samples used in this research were obtained from The Cancer Genome Atlas (TCGA) at https://genome-cancer.ucsc.edu, including $528 \mathrm{ccRCC}$, 288 pRCC and 66 chRCC samples. Fifty human HMTs were analyzed. In addition, 78 samples of Tokyo university downloaded from cBioportal were added to persuasively compare the tumor stage and overall survival between 62 SET-domain mutated patients and 16 non-SET-domain mutated patients. The copy number of HMTs is generated by the copy number algorithm GISTIC (Genomic Identification of Significant Targets in Cancer) algorithm analysis: "-2" represents a homozygous deletion, "-1" indicates a heterozygous deletion, "0" represents diploid, "1" indicates a low-level gain, and "2" signifies a high-level amplification. For mRNA expression data, the relative expression and gene expression profiles in the RCC samples were analyzed.

\section{Statistical analysis}


81 (version 7.01) and SPSS (version 18.0). The correlations between copy number alteration (CNA) and mutation status of 50 HMTs and 882 phenotypes of specimens were analyzed using Chisquare test. The CNA and mRNA expression of 46 HMTs from 882 sequenced RCC specimens were analyzed using Spearman, Kendall, and Pearson correlation tests. KMT2A, KMT2C,

KMT2D and KMT2E were excluded for lack of data. Heatmap of HMTs expression profiles in different subtypes of renal cell carcinoma was conducted by R statistical software. The Student's

t-test was used in calculating differences in mRNA expression levels of each HMT between ccRCC and other subtypes. Kaplan-Meier survival curve was conducted to analysis the impact of CNA or gene expression of different HMTs on survival. Multivariate survival analysis was performed to investigate prognosis factors by Cox regression. The mRNA relative expression levels were analyzed by one-way analysis of variance. $\mathrm{P}<0.05$ was considered statistically significant.

\section{Gene Set Enrichment Analysis}

Gene Set Enrichment Analysis (GSEA) was performed by GSEA software (Version 2.2.2), which was downloaded from the Broad Institute (http://www.broad.mit.edu/gsea). Enrichment map was generated for visualization of the GSEA results. False discovery rate (FDR) value, normalized enrichment score (NES) and adjusted $\mathrm{P}$ value were calculated to identify the Hallmarks enriched in each phenotype.

\section{Cell culture}


101

102

103

104

105

106

107

108

109

110

111

112

113

114

115

116

117

118

119

120

121

supplemented with $10 \%$ fetal bovine serum in an atmosphere at $37^{\circ} \mathrm{C}$ with $5 \% \mathrm{CO}_{2} .786-\mathrm{O}$ and

OSRC-2 cells were cultured in RPMI-1640 supplemented with 10\% fetal bovine serum in an atmosphere at $37^{\circ} \mathrm{C}$ with $5 \% \mathrm{CO}_{2}$.

\section{Quantitative real-time PCR}

Total RNAs were extracted by MagZol (Invitrogen, USA) and cDNAs were synthetized by using SYBR Premix Ex TaqTM (TaKaRa, Japan). Real-time PCR was performed by SYBR Green Realtime PCR Master Mix (TOYOBO, Japan). Amplification conditions were as follows: $95^{\circ} \mathrm{C}$ for $15 \mathrm{~s}, 60^{\circ} \mathrm{C}$ for $30 \mathrm{~s}, 72^{\circ} \mathrm{C}$ for $30 \mathrm{~s}$ for 40 cycles in a $20 \mu 1$ reaction mix containing $2 \times$ SYBR Green. Primers for the reaction are provided in Supplementary Table 1.

\section{Plasmids}

The shRNA plasmids for SETD2 and EZH2 knockdown were constructed from pSicoR (Addgene, \#11579) with target sequences of shSETD2: TAGTACACCAAGACTCCAG, and shEZH2: CCAACACAAGTCATCCCATTA. All plasmids were verified by sequencing.

\section{Cell viability, cell proliferation, cell migration and invasion assays}

Cell viability was assessed at 0, 24, 48, 72 and 96 hours upon treatments by the 3-(4,5dimethylthiazol-2-yl)-5-(3-carboxymethoxyphenyl)-2-(4-sulfophenyl)-2H-tetrazolium, inner salt (MTS) method (Promega, \#0000253755) according to the manufacturer's instructions. The MTS have six replications. Cell proliferation was estimated using the cell-light EdU Apollo 568 in vitro kit (Ribobio, \#C10310-1) according to the manufacturer's instructions. Migration and invasion assays were performed using uncoated and Matrigel-coated Transwell inserts according to manufacturer's instructions. All experiments were performed in triplicate. 
122

123

124

125

126

127

128

129

130

131

132

133

134

135

136

137

138

139

140

141

142

\section{Results}

\section{Genetic alterations of HMTs in renal cell carcinoma}

Copy number alteration and somatic mutations are crucial mechanisms for oncogenesis or inactivating tumor suppressor genes in the occurrence and development of cancer (Albertson et al., 2003). We hypothesized that genetic alterations of HMTs play significant roles in the development and progression of renal cell carcinoma (Pires-Luis et al., 2015). To systematically identify HMTs' potential of being biomarkers of diagnosis and prognosis of RCC, we first analyzed copy numbers and mutations of 882 renal cell carcinoma samples from the TCGA database via Cancer Browser (Yao et al., 2016). In Cancer Browser CNA datasets of RCC, as previously described, CNA was counted as "-2", “-1", "0", "1" and "2", and the average CNA rate of 50 HMTs was -0.0066 . We found a different pattern of altered copy number and mutation of HMTs in renal cell carcinoma. Strikingly, as showed in Table 2, seven HMTs (NSD1, PRDM6, MECOM, KMT2C, EZH2, PRDM14 and KMT2E) exhibited high-level amplification in more than $0.5 \%$ of renal cell carcinoma samples, and two of these seven HMTs (NSD1 and PRDM6) had a much higher amplification rate in over $10 \%$ of ccRCC samples. Three HMT genes, SETD2, SETD5 and SETMAR, showed homozygous deletion in more than 10\% ccRCC samples. Intriguingly, NSD1 and PRDM6, the highest frequency of the top two HMTs with highlevel amplification, were located in chromosome 5q; whereas SETD2, SETD5 and SETMAR, the highest frequency of the top three HMTs with homozygous deletion, were located in chromosome 3p. Additionally, KMT2C and SETD2 exhibited somatic mutations in more than $6 \%$ of ccRCC samples. Several studies revealed that SETD2 was frequently mutated in ccRCC 
143 and SETD2-mutated signal pathway played a vital role in the process of oncogenesis (Li et al.,

144 2016; Wang et al., 2015; Li et al., 2016). Analogously, in our study SETD2 showed the highest

145 mutation rate (11.51\%) among 50 HMTs in ccRCC (Table 2).

146 Furthermore, HMTs showed different frequencies of CNA and mutation in different

147 subtypes of renal cell carcinoma. Among the seven most frequently amplified HMTs, the

148 frequencies of NSD1 and PRDM6 of high-level amplification were markedly higher in 528

149 ccRCC with more than $13.45 \%$ of tumor samples exhibiting amplificated when compared with

150 that of $288 \mathrm{pRCC}$ and $66 \mathrm{chRCC}$ subtypes, which was less than 1.04\% of tumor samples (Figure

151 1A). Also, SETD2 and SETD5 exhibited the highest frequency of homozygous deletion in

152 ccRCC. However, neither of them exhibited homozygous deletion in pRCC and chRCC subtypes

153 (Figure 1B). Additionally, in $213 \mathrm{ccRCC}, 113 \mathrm{pRCC}$ and 65 chRCC, of the most commonly

154 mutated HMTs, SETD2 and KMT2C were most frequently mutated in ccRCC and pRCC

155 subtypes, whereas SETD2 was mutated in less than $1.54 \%$ of tumor samples and KMT2C did not

156 exhibit mutation in chRCC (Figure 1C). The above data indicates that the subtype of ccRCC has

157 a higher CNA and somatic mutation frequency in several HMTs, including amplification of

158 NSD1 and PRDM6, homozygous deletion of SETD2, SETD5 and SETMAR, and mutation of

159 KMT2C and SETD2.

160 Gene expression and CNA profiling of HMTs in renal cell carcinoma

161 The correlation between gene expression and copy number has been associated with the

162 detection of human oncogenes. Therefore, we analyzed the correlation between copy number and

gene expression level of 46 HMTs from 882 sequenced renal cell carcinoma samples which were 
164

165

166

167

168

169

170

171

172

173

174

175

176

177

178

179

180

181

182

183

184

divided into ccRCC and non-ccRCC (KIRP+KICH) groups. Four HMTs (KMT2A, KMT2C,

KMT2D and KMT2E) were excluded for lack of data. The rank correlation coefficients in the

three statistical tests were similar for HMTs (Table 3). As shown in Table 3, HMTs were ranked

based on the Spearman correlation coefficient, and the correlations between CNA and mRNA

expression of 46 HMT genes were positive, and three of them (NSD1, WHSC1L1, SETDB1)

showed a Spearman correlation coefficient greater than 0.5. $(\mathrm{P}<0.0001)$. WHSC1L1 exhibited

the highest correlation coefficient by Pearson $(r=0.669)$, Spearman $(r=0.689)$ and Kendall

$(\mathrm{r}=0.596)$. Meanwhile, to investigate the degree of discretization of the data sets, the standard

deviations of mRNA expression between the ccRCC and non-ccRCC subtypes was performed.

As shown in the Table 3, PRDM6 in ccRCC group had a higher degree of discretization than that

of in non-ccRCC group.

Expression levels of the 46 HMTs was compared in the heatmap. Compared with non-

ccRCC, mRNA levels of 10 HMTs (PRDM1, PRDM8, MECOM, PRDM16, SETD7, PRDM5,

ASH1L, NSD1, SUV39H2 and SETDB1) were significantly higher $(p<0.001)$ and 10 HMTs

(PRDM12, SUV420H2, SETMAR, SETD1A, SETD2, SETD4, PRDM4, SETD8, DOT1L and

SETD1B) were significantly lower $(\mathrm{p}<0.001)$ in ccRCC (Figure 2 and Supplemental Table 2).

\section{SETD2 and KMT2C mutations in clear cell renal cell carcinoma}

As described previously, we found that SETD2 and KMT2C are most frequently mutated

HMTs in ccRCC, at rates of $11.51 \%$ and $6.10 \%$ (Table 2). A systematic analysis of these

mutation profiles was performed in ccRCC samples. Results showed that a total of 78 SETD2

mutations were found whereas 14 mutations were excluded because their data were untested. 64 
185

186

187

mutations were valid, including 18 nonsense mutations, 21 missense mutations, 5 frameshift insertions, 8 frameshift deletions, 6 splices, and 3 other mutations. In addition, 24 KMT2C gene mutations were identified, including 10 missense mutations, 5 nonsense mutations, 3 frameshift deletions, 2 splice, and 4 other mutations (Figure 3A). A mutation map was performed to display the distribution of SETD2 and KMT2C mutations (Figure 3B). By systematic analysis of the mutation distribution, we found that SETD2 mutations were more likely to occur at SET domain area. Taking account of the crucial function of SET domain in SETD2, we predicted that mutations at the SET domain might result in the loss of methyltransferases features of SETD2 and poor prognosis of ccRCC patients. Therefore, we performed a Kaplan-Meier plots to investigate the clinical features between SETD2 SET domain mutation group and non-SET domain mutation group; results indicated that SETD2 SET domain mutation group was featured with advanced tumor stage and poor prognosis in ccRCC (Figure 4A).

\section{Identification of SET-Domain associated biological process by GSEA}

To identify SET-Domain associated biological process and function loss of SETD2 on a generalized level, Gene Set Enrichment Analysis (GSEA) was performed by using high throughput RNA-sequencing data of the TCGA cohort. The mutation state of SET domain was used as the phenotype label. Among all the predefined Hallmarks gene sets, DNA repair, E2F targets, G2M checkpoint and mitotic spindle were found to be significantly associated with SET domain mutation in the TCGA cohort (Figure 4B).

\section{HMTs CNA and expression and clear cell renal cell carcinoma patient survival}

To explore the clinical association of genetic alterations of HMTs in renal cell carcinoma, 
206 207 208 209

we investigated the association between CNA, mRNA expression, and overall patient survival in 452 ccRCC samples, 76 ccRCC samples were excluded because their detailed survival data is not available in TCGA database. First of all, samples were divided into the following three groups for each HMT: amp/gain (high-level amplification/low-level gain), diploid, and deletion. For six HMTs (EZH2, NSD1, PRDM6, SETD2, SETD5 and SETMAR), copy number amp/gain and deletion were significantly related to poorer survival in renal cell carcinoma patients $(\mathrm{p}<0.05)$. Deletions of KMT2C and PRDM6 were related to shorter survival, however, only amp/gain of EZH2 and PRDM14 was more likely related to poorer survival. More importantly, deletion of NSD1 was significantly related to poorer survival; amp/gain of NSD1 was significantly related to longer survival, compared with diploid or deletion groups (Figure 5A and Supplemental Figure 1).

To analyze the relationship between HMTs expression and overall survival of ccRCC patients, they were divided into low $(n=226)$ and high $(n=226)$ expression groups based on the mRNA expression of each HMT. High mRNA levels of EZH2, PRDM6, SETD5 and SETMAR were significantly associated with shorter survival in ccRCC patients, whereas only high NSD1 expression was correlated with longer survival in ccRCC $(\mathrm{p}<0.05)$ (Figure 5A and Supplemental Figure 1).

A multivariate analysis by Cox model $(n=428)$ was performed to investigate the capability to predict poor prognosis of each HMT compared with standard prognostic markers, such as age at diagnosis, gender and tumor stage (stage I to stageIV). Results indicated that amp/gain of ASH1L had a hazard radio (HR), a ratio of death probabilities, of 1.533 compared with non- 
227

228

229

230

231

232

233

234

235

236

237

238

239

240

241

242

243

244

245

246

247

amp/gain of ASH1L in RCC patients. In addition, deletion of PRDM8 was significantly

associated with shorter survival $(\mathrm{HR}=1.516, \mathrm{P}<0.05)$ in $\mathrm{RCC}$ patients. High mRNA levels of

SETD1A $(\mathrm{HR}=1.275)$ and PRDM9 $(\mathrm{HR}=1.258)$ was significantly associated with shorter

survival in $\mathrm{RCC}$ patients $(\mathrm{P}<0.05)$. However, higher expression of PRDM8 $(\mathrm{HR}=0.739)$,

EHMT1 $(\mathrm{HR}=0.723)$, ASH1L $(\mathrm{HR}=0.711)$, WHSC1L1 $(\mathrm{HR}=0.674)$ and SUV420H1(HR=0.616)

was negatively associated with shorter survival in RCC patients $(\mathrm{P}<0.05)$. Also, amp/gain of

PRDM6 (HR=0.703), PRDM9 (HR=0.662), PRDM7 (HR=0.640), SETD1A (HR=0.638), NSD1

$(\mathrm{HR}=0.598)$ and DOT1L $(\mathrm{HR}=0.592)$ was negative correlated with shorter survival in $\mathrm{RCC}$

patients $(\mathrm{P}<0.05)$. (Figure 5B and Supplemental Table 3).

\section{RT-PCR analysis of mRNA expression of important HMTs}

Quantitative RT-PCR was performed to measure the expression level of eight important

HMTs (NSD1, PRDM6, MECOM, EZH2, ASH1L, SETD1A, WHSC1L1 and SETD2). HK-2, a

renal tubular epithelial cell line, was used as the control group. Relative expression of the eight

HMTs in kidney cancer cell lines compared with HK-2 cell line was shown in Figure 6. It

showed that mRNA levels of EZH2 were more than four-fold higher in kidney cancer cell lines.

In contrast, mRNA levels of WHSC1L1, ASH1L and NSD1 were more than one-fold lower in

kidney cancer cell lines. Notably, for SETD2 and MECOM, mRNA levels were more than three-

fold and six-fold lower in kidney cancer cell lines, respectively. However, mRNA level of

PRDM6 did not show significant difference between RCC and control cell lines. These results

indicated that there was a correlated change between CNAs and mRNA expression.

\section{Comprehensive identification of important HMTs in RCC}


that these six HMTs may play important roles in RCC oncogenesis.

SETD2 inhibits cell proliferation in vitro, EZH2 promotes cell proliferation, migration and

\section{invasion in vitro}

We performed MTS assays, Transwell migration/invasion assays and EdU assays in 786-O

cell line to detect the function on cell proliferation and migration of SETD2 and EZH2. Assays

showed a higher proliferative ability in 786-O cell line with SETD2 knockdown. However, the

migration and invasion ability showed no significant differences with or without SETD2

knockdown. Meanwhile EZH2 knockdown reduced the ability of cell proliferation, migration

and invasion significantly. Results mentioned above (Figure 7,8) were consistent with our

preceding findings.

\section{Discussion}

We performed a systematic analysis of 50 human HMTs in RCC samples of TCGA and 
269

270

271

272

273

274

275

276

277

278

279

280

281

282

between gene expression and CNA was identified: all 46 HMTs showed a positive correlation and three HMTs (NSD1, WHSC1L1, SETDB1) had a Spearman correlation coefficient (r) greater than 0.5. WHSC1L1 exhibited the highest correlation; (4) Compared with non-ccRCC, mRNA levels of 10 HMTs (PRDM1, PRDM8, MECOM, PRDM16, SETD7, PRDM5, ASH1L, NSD1, SUV39H2 and SETDB1) were significantly higher and 10 HMTs (PRDM12, SUV420H2, SETMAR, SETD1A, SETD2, SETD4, PRDM4, SETD8, DOT1L and SETD1B) were significantly lower in ccRCC; (5) the top two mutated HMTs, KMT2C and SETD2, showed various of mutations at the SET domain in which many of SETD2 mutation were located, leading to loss of their methyltransferase functions; (6) we identified six HMTs (EZH2, NSD1, PRDM6, SETD2, SETD5 and SETMAR) which DNA copy number or mRNA expression level was significantly related to poorer survival in renal cell carcinoma patients; (7) mRNA levels of NSD1, WHSC1L1, ASH1L, SETD2 and MECOM were lower in renal cancer cells compared with renal tubular epithelial cell line whereas EZH2 and SETD1A exhibited the opposite; (8) SETD2 inhibits cell proliferation in vitro, EZH2 promotes cell proliferation, migration and invasion in vitro.

Oncogenic alterations of HMTs, including amplification, homozygous deletion and mutation, were associated with various human cancers, including RCC (Qu et al., 2016; Li et al., 2016; Piva et al., 2015a). EZH2 is overexpressed and mutated frequently in RCC and other types of tumors, contributing to tumorigenic potential of cancer (Chen et al., 2017). SETD2 is also a common tumor suppressor gene at chromosome $3 \mathrm{p} 21$, which is found to be mutated frequently in RCC (Piva et al., 2015b; Wang et al., 2015; Ho et al., 2016). 
chromosome $5 \mathrm{q}$ were uncovered in ccRCC patients and presented their prognostic and diagnostic

292

293

294

295

296

297

298

299

300

301

302

303

304

305

306

307

308

309

310

potential (Nagao et al., 2005; Kluzek et al., 2017; Togo et al., 2016). Taking chromosome 3p as

an illustration, ccRCC was characterized by a high frequency of allelic deletion or loss of

heterozygosity on chromosome $3 p$, causing biallelic mutation or promoter hypermethylation of

von Hippel-Lindau (VHL) gene. Similarly, our results indicated that SETD2, SETD5 and

SETMAR were frequently deleted in ccRCC and they were located at $3 p$, implying their

potential roles as tumor suppressors. Several researches explored their relationship between

methylation of VHL promotor, SETD2 mutation and copy number alteration of other genes

located at 3p, including SETD5 and BAP1. As shown in table 3, WHSC1L1 showed the highest

correlation between CNA and expression level and oncogenic potential in ccRCC, which was

coincidently consistent with that of in breast cancer (Liu et al., 2015). Intriguingly, ccRCC

patients were divided into two groups by WHSC1L1 mRNA expression level and the low

expression group exhibited poorer prognosis, which was opposite from the role of WHSC1L1 in

other cancers (Saloura et al., 2017; Irish et al., 2016).

SETD2 was most mutated in ccRCC with highest frequency rate of $11.51 \%$. SETD2 SET

domain played a critical effect on affecting tumor stage of ccRCC patients. Clinical stage of

patients with SETD2 mutations occurred in SET domain region were often higher than those of

patients whose SETD2 mutations did not located in SET domain. Taking our results of the GO

enrichment analysis into account, among all the predefined Hallmarks gene sets, DNA repair,

E2F targets, G2M checkpoint and mitotic spindle were found to be significantly associated with 
311 SET domain mutation, suggesting that SET domain mutation may be involved in ccRCC

312 development and progression through the above cancer-associated biological processes (Piva et

313 al., 2015; Hacker et al., 2016; Park et al., 2016). The above potential pathway involved in DNA

314 repair, cell circle, dual chromatin and cytoskeletal remodeling might constitute the reason for

315 poor prognosis in patients with SETD2 mutations. Cell experiments revealed that SETD2

316 inhibits cell proliferation; however, the migration and invasion ability showed no significant

317 differences. In numerous experimental settings, it has been established that SETD2 regulate cell

318 growth in human cancers (Jiang et al., 2018; Feodorova et al., 2018). Targeting SETD2 is

319 believed to be a promising strategy for cancer therapy. However, an incomplete understanding of

320 the molecular mechanisms that regulate SETD2 remains a barrier.

321 Furthermore, the other important HMTs including NSD1, PRDM6, EZH2, SETD5,

322 WHSC1L1 and SETMAR were significantly associated with shorter survival in renal cell

323 carcinoma patients. Except for EZH2, few of them were frequently identified and studied in

324 kidney cancer. SETD5 was reported and identified as a new diagnostic marker in prostate cancer

325 (Sowalsky et al., 2015), which was consistent with our research. EZH2 is highly expressed in

numerous cancers, including renal cell carcinoma (Wagener et al., 2010b; Azizmohammadi et

al., 2017; Lv et al., 2015; Wagener et al., 2008b). Our findings showed that high EZH2

expression level was associated with tumor cell lines and poorer prognosis and in vitro

experiments testified that EZH2 promoted cell proliferation, migration and invasion in ccRCC.

These results were consistent with preceding literature (Avissar-Whiting et al., 2011; Hinz et al., 
332 that it may be essential for the maintenance of malignant phenotypes of renal cancers.

333

334

335

336

337

338

339

340

341

342

343

344

345

346

347

348

349

350

351

352

\section{Conclusions}

In summary, our findings strongly evidenced that genetic alteration of HMTs may play an important role in generation and development of renal cell carcinoma, which lays a solid foundation for the mechanism for further research in the future.

\section{Acknowledgements}

We thank Dr. Ke Chen for his advice.

\section{References}

Albert, M., and Helin, K. 2010. Histone methyltransferases in cancer. SEMINARS IN CELL \& DEVELOPMENTAL BIOLOGY 21:209-220. 10.1016/j.semcdb.2009.10.007

Albertson, D.G., Collins, C., McCormick, F., and Gray, J.W. 2003. Chromosome aberrations in solid tumors. NATURE GENETICS 34:369-376. 10.1038/ng1215

Avissar-Whiting, M., Koestler, D.C., Houseman, E.A., Christensen, B.C., Kelsey, K.T., and Marsit, C.J. 2011. Polycomb group genes are targets of aberrant DNA methylation in renal cell carcinoma. Epigenetics 6:703-709.

Azizmohammadi, S., Azizmohammadi, S., Safari, A., Kaghazian, M., Sadrkhanlo, M., Behnod, V., and Seifoleslami, M. 2017. High-Level Expression of RIPK4 and EZH2 Contributes to Lymph Node Metastasis and Predicts Favorable Prognosis in Patients With Cervical Cancer. ONCOLOGY RESEARCH 25:495-501. 10.3727/096504016X14749735594687

Chen, K., Xiao, H., Zeng, J., Yu, G., Zhou, H., Huang, C., Yao, W., Xiao, W., Hu, J., Guan, W., Wu, L., Huang, J., Huang, Q., Xu, H., and Ye, Z. 2017. Alternative Splicing of EZH2 pre-mRNA 
353 by SF3B3 Contributes to the Tumorigenic Potential of Renal Cancer. CLINICAL CANCER 354 RESEARCH 23:3428-3441. 10.1158/1078-0432.CCR-16-2020

355 Feodorova, Y., Tashkova, D., Koev, I., Todorov, A., Kostov, G., Simitchiev, K., Belovejdov, V., 356 Dimov, R., and Sarafian, V. 2018. Novel insights into transcriptional dysregulation in colorectal 357 cancer. NEOPLASMA 65:415-424. 10.4149/neo_2018_170707N467

358 Greer, E.L., and Shi, Y. 2012. Histone methylation: a dynamic mark in health, disease and 359 inheritance. NATURE REVIEWS GENETICS 13:343-357. 10.1038/nrg3173

360 Hacker, K.E., Fahey, C.C., Shinsky, S.A., Chiang, Y.J., DiFiore, J.V., Jha, D.K., Vo, A.H., Shavit, J.A., Davis, I.J., Strahl, B.D., and Rathmell, W.K. 2016. Structure/Function Analysis of Recurrent

Mutations in SETD2 Protein Reveals a Critical and Conserved Role for a SET Domain Residue in

Maintaining Protein Stability and Histone H3 Lys-36 Trimethylation. JOURNAL OF BIOLOGICAL CHEMISTRY 291:21283-21295. 10.1074/jbc.M116.739375

Herz, H.M., Garruss, A., and Shilatifard, A. 2013. SET for life: biochemical activities and biological functions of SET domain-containing proteins. TRENDS IN BIOCHEMICAL SCIENCES 38:621-639. 10.1016/j.tibs.2013.09.004

Hinz, S., Weikert, S., Magheli, A., Hoffmann, M., Engers, R., Miller, K., and Kempkensteffen, C. 2009. Expression profile of the polycomb group protein enhancer of Zeste homologue 2 and its prognostic relevance in renal cell carcinoma. J Urol 182:2920-2925. 10.1016/j.juro.2009.08.014 
374 specific death. Mod Pathol 29:34-42. 10.1038/modpathol.2015.123

375 Irish, J.C., Mills, J.N., Turner-Ivey, B., Wilson, R.C., Guest, S.T., Rutkovsky, A., Dombkowski, 376 A., Kappler, C.S., Hardiman, G., and Ethier, S.P. 2016. Amplification of WHSC1L1 regulates 377 expression and estrogen-independent activation of ER $\alpha$ in SUM-44 breast cancer cells and is 378 associated with ER $\alpha$ over-expression in breast cancer. Molecular Oncology 10:850-865. 10.1016/j.molonc.2016.02.003

Jiang, C., He, C., Wu, Z., Li, F., and Xiao, J. 2018. Histone methyltransferase SETD2 regulates osteosarcoma cell growth and chemosensitivity by suppressing Wnt/beta-catenin signaling. Biochem Biophys Res Commun 502:382-388. 10.1016/j.bbrc.2018.05.176

Kanu, N., Gronroos, E., Martinez, P., Burrell, R.A., Yi, G.X., Bartkova, J., Maya-Mendoza, A.,

Mistrik, M., Rowan, A.J., Patel, H., Rabinowitz, A., East, P., Wilson, G., Santos, C.R.,

McGranahan, N., Gulati, S., Gerlinger, M., Birkbak, N.J., Joshi, T., Alexandrov, L.B., Stratton,

M.R., Powles, T., Matthews, N., Bates, P.A., Stewart, A., Szallasi, Z., Larkin, J., Bartek, J., and

Swanton, C. 2015. SETD2 loss-of-function promotes renal cancer branched evolution through replication stress and impaired DNA repair. ONCOGENE 34:5699-5708. 10.1038/onc.2015.24

Kluzek, K., Srebniak, M.I., Majer, W., Ida, A., Milecki, T., Huminska, K., van der Helm, R.M.,

Silesian, A., Wrzesinski, T.M., Wojciechowicz, J., Beverloo, B.H., Kwias, Z., Bluyssen, H., and

Wesoly, J. 2017. Genetic characterization of Polish ccRCC patients: somatic mutation analysis of

PBRM1, BAP1 and KDMC5, genomic SNP array analysis in tumor biopsy and preliminary results of chromosome aberrations analysis in plasma cell free DNA. Oncotarget 8:28558-28574. 
Li, J., Duns, G., Westers, H., Sijmons, R., van den Berg, A., and Kok, K. 2016. SETD2: an

396 epigenetic modifier with tumor suppressor functionality. Oncotarget 7:50719-50734.

397

398

399

400

401

402

403

404

405

406

407

408

409

410

411

412

413

414

415

\subsection{2/oncotarget.9368}

Li, J., Kluiver, J., Osinga, J., Westers, H., van Werkhoven, M.B., Seelen, M.A., Sijmons, R.H., van den Berg, A., and Kok, K. 2016. Functional Studies on Primary Tubular Epithelial Cells Indicate a Tumor Suppressor Role of SETD2 in Clear Cell Renal Cell Carcinoma. NEOPLASIA 18:339-346. 10.1016/j.neo.2016.04.005

Liu, L., Kimball, S., Liu, H., Holowatyj, A., and Yang, Z.Q. 2015. Genetic alterations of histone lysine methyltransferases and their significance in breast cancer. Oncotarget 6:2466-2482. 10.18632/oncotarget.2967

Lv, Y.F., Yan, G.N., Meng, G., Zhang, X., and Guo, Q.N. 2015. Enhancer of zeste homolog 2 silencing inhibits tumor growth and lung metastasis in osteosarcoma. Sci Rep 5:12999. $10.1038 /$ srep 12999

Nagao, K., Yamaguchi, S., Matsuyama, H., Korenaga, Y., Hirata, H., Yoshihiro, S., Fukunaga, K., Oba, K., and Naito, K. 2005. Allelic loss of 3p25 associated with alterations of 5q22.3 approximately q23.2 may affect the prognosis of conventional renal cell carcinoma. Cancer Genet Cytogenet 160:43-48. 10.1016/j.cancergencyto.2004.11.015

Niu, X., Zhang, T., Liao, L., Zhou, L., Lindner, D.J., Zhou, M., Rini, B., Yan, Q., and Yang, H. 2012. The von Hippel-Lindau tumor suppressor protein regulates gene expression and tumor growth through histone demethylase JARID1C. ONCOGENE 31:776-786. 10.1038/onc.2011.266

Park, I.Y., Powell, R.T., Tripathi, D.N., Dere, R., Ho, T.H., Blasius, T.L., Chiang, Y.C., Davis, 
416 I.J., Fahey, C.C., Hacker, K.E., Verhey, K.J., Bedford, M.T., Jonasch, E., Rathmell, W.K., and

417 Walker, C.L. 2016. Dual Chromatin and Cytoskeletal Remodeling by SETD2. CELL 166:950-962.

$418 \quad$ 10.1016/j.cell.2016.07.005

419 Pires-Luís, A.S., Vieira-Coimbra, M., Vieira, F.Q., Costa-Pinheiro, P., Silva-Santos, R., Dias, 420 P.C., Antunes, L., Lobo, F., Oliveira, J., Gon Alves, C.S., Costa, B.M., Henrique, R., and Jerónimo,

C. 2015. Expression of histone methyltransferases as novel biomarkers for renal cell tumor diagnosis and prognostication. 10:1033-1043. 10.1080/15592294.2015.1103578

423 Pires-Luis, A.S., Vieira-Coimbra, M., Vieira, F.Q., Costa-Pinheiro, P., Silva-Santos, R., Dias, 424 P.C., Antunes, L., Lobo, F., Oliveira, J., Goncalves, C.S., Costa, B.M., Henrique, R., and Jeronimo, C. 2015. Expression of histone methyltransferases as novel biomarkers for renal cell tumor diagnosis and prognostication. Epigenetics 10:1033-1043. 10.1080/15592294.2015.1103578

427 Piva, F., Giulietti, M., Occhipinti, G., Santoni, M., Massari, F., Sotte, V., Iacovelli, R., Burattini, L., Santini, D., Montironi, R., Cascinu, S., and Principato, G. 2015. Computational analysis of the mutations in BAP1, PBRM1 and SETD2 genes reveals the impaired molecular processes in renal cell carcinoma. Oncotarget 6:32161. 10.18632/oncotarget.5147

Piva, F., Santoni, M., Matrana, M.R., Satti, S., Giulietti, M., Occhipinti, G., Massari, F., Cheng,

L., Lopez-Beltran, A., Scarpelli, M., Principato, G., Cascinu, S., and Montironi, R. 2015a. BAP1,

PBRM1 and SETD2 in clear-cell renal cell carcinoma: molecular diagnostics and possible targets for personalized therapies. EXPERT REVIEW OF MOLECULAR DIAGNOSTICS 15:1201-1210.

Piva, F., Santoni, M., Matrana, M.R., Satti, S., Giulietti, M., Occhipinti, G., Massari, F., Cheng, 
437 L., Lopez-Beltran, A., Scarpelli, M., Principato, G., Cascinu, S., and Montironi, R. 2015b. BAP1,

438 PBRM1 and SETD2 in clear-cell renal cell carcinoma: molecular diagnostics and possible targets

439 for personalized therapies. EXPERT REVIEW OF MOLECULAR DIAGNOSTICS 15:1201-1210.

$440 \quad 10.1586 / 14737159.2015 .1068122$

441 Qu, Y., Liu, L., Wang, J., Xi, W., Xia, Y., Bai, Q., Xiong, Y., Long, Q., Xu, J., and Guo, J. 2016.

442 Dot11 expression predicts adverse postoperative prognosis of patients with clear-cell renal cell

443 carcinoma. Oncotarget 7:84775-84784. 10.18632/oncotarget.12476

444 Roy, D.M., Walsh, L.A., and Chan, T.A. 2014. Driver mutations of cancer epigenomes. Protein \&

445 Cell 5:265-296. 10.1007/s13238-014-0031-6

446 Saloura, V., Vougiouklakis, T., Zewde, M., Deng, X., Kiyotani, K., Park, J.H., Matsuo, Y., Lingen,

447 M., Suzuki, T., Dohmae, N., Hamamoto, R., and Nakamura, Y. 2017. WHSC1L1-mediated EGFR

448 mono-methylation enhances the cytoplasmic and nuclear oncogenic activity of EGFR in head and

449 neck cancer. Sci Rep 7:40664. 10.1038/srep40664

450 Shen, H., and Laird, P.W. 2013. Interplay between the cancer genome and epigenome. CELL

$451 \quad$ 153:38-55. 10.1016/j.cell.2013.03.008

452 Siegel, R., Ma, J., Zou, Z., and Jemal, A. 2014. Cancer statistics, 2014. CA Cancer J Clin 64:9-29.

$453 \quad 10.3322 /$ caac. 21208

454 Sowalsky, A.G., Xia, Z., Wang, L., Zhao, H., Chen, S., Bubley, G.J., Balk, S.P., and Li, W. 2015.

455 Whole transcriptome sequencing reveals extensive unspliced mRNA in metastatic castration-

456 resistant prostate cancer. MOLECULAR CANCER RESEARCH 13:98-106. 10.1158/1541-

457 7786.MCR-14-0273 
458 Tian, X., Zhang, S., Liu, H.M., Zhang, Y.B., Blair, C.A., Mercola, D., Sassone-Corsi, P., and Zi, 459 X. 2013. Histone lysine-specific methyltransferases and demethylases in carcinogenesis: new

460

461

462

463

464

465

466

467

468

469

470

471

472

473

474

475

476

477

478

targets for cancer therapy and prevention. Curr Cancer Drug Targets 13:558-579.

Tiedemann, R.L., Hlady, R.A., Hanavan, P.D., Lake, D.F., Tibes, R., Lee, J.H., Choi, J.H., Ho,

T.H., and Robertson, K.D. 2016. Dynamic reprogramming of DNA methylation in SETD2deregulated renal cell carcinoma. Oncotarget 7:1927-1946. 10.18632/oncotarget.6481

Togo, Y., Yoshikawa, Y., Suzuki, T., Nakano, Y., Kanematsu, A., Zozumi, M., Nojima, M., Hirota, S., Yamamoto, S., and Hashimoto-Tamaoki, T. 2016. Genomic profiling of the genes on chromosome $3 \mathrm{p}$ in sporadic clear cell renal cell carcinoma. INTERNATIONAL JOURNAL OF ONCOLOGY 48:1571-1580. 10.3892/ijo.2016.3395

Vieira-Coimbra, M., Henrique, R., and Jeronimo, C. 2015. New insights on chromatin modifiers and histone post-translational modifications in renal cell tumours. EUROPEAN JOURNAL OF CLINICAL INVESTIGATION 45 Suppl 1:16-24. 10.1111/eci.12360

Wagener, N., Holland, D., Bulkescher, J., Crnkovic-Mertens, I., Hoppe-Seyler, K., Zentgraf, H., Pritsch, M., Buse, S., Pfitzenmaier, J., Haferkamp, A., Hohenfellner, M., and Hoppe-Seyler, F. 2008a. The enhancer of zeste homolog 2 gene contributes to cell proliferation and apoptosis resistance in renal cell carcinoma cells. INTERNATIONAL JOURNAL OF CANCER 123:15451550. $10.1002 / \mathrm{ijc} .23683$

Wagener, N., Holland, D., Bulkescher, J., Crnkovic-Mertens, I., Hoppe-Seyler, K., Zentgraf, H., Pritsch, M., Buse, S., Pfitzenmaier, J., Haferkamp, A., Hohenfellner, M., and Hoppe-Seyler, F. 2008b. The enhancer of zeste homolog 2 gene contributes to cell proliferation and apoptosis 
479

480

481

482

483

484

485

486

487

488

489

490

491

492

493

494

495

496

497

498 resistance in renal cell carcinoma cells. INTERNATIONAL JOURNAL OF CANCER 123:1545-

1550. $10.1002 / \mathrm{ijc} .23683$

Wagener, N., Macher-Goeppinger, S., Pritsch, M., Husing, J., Hoppe-Seyler, K., Schirmacher, P., Pfitzenmaier, J., Haferkamp, A., Hoppe-Seyler, F., and Hohenfellner, M. 2010a. Enhancer of zeste homolog 2 (EZH2) expression is an independent prognostic factor in renal cell carcinoma. $B M C$ CANCER 10:524. 10.1186/1471-2407-10-524

Wagener, N., Macher-Goeppinger, S., Pritsch, M., Husing, J., Hoppe-Seyler, K., Schirmacher, P., Pfitzenmaier, J., Haferkamp, A., Hoppe-Seyler, F., and Hohenfellner, M. 2010b. Enhancer of zeste homolog 2 (EZH2) expression is an independent prognostic factor in renal cell carcinoma. $B M C$ CANCER 10:524. 10.1186/1471-2407-10-524

Wang, J., Wen, J., Yi, R., Liu, F., Zhou, J., Liu, G., Li, Q., Yang, Z., and Su, X. 2015. High selectivity of PI3K $\beta$ inhibitors in SETD2-mutated renal clear cell carcinoma. Journal of B.U.ON. : official journal of the Balkan Union of Oncology 20:1267.

Yan, B.C., Mackinnon, A.C., and Al-Ahmadie, H.A. 2009. Recent developments in the pathology of renal tumors: morphology and molecular characteristics of select entities. ARCHIVES OF PATHOLOGY \& LABORATORY MEDICINE 133:1026-1032. 10.1043/1543-2165-133.7.1026

Yao, T., Wang, Q., Zhang, W., Bian, A., and Zhang, J. 2016. Identification of genes associated with renal cell carcinoma using gene expression profiling analysis. Oncology Letters 12:73-78. $10.3892 / 01.2016 .4573$ 
Figure 1

Frequencies of CNA of HMTs

(A) High-level amplifcation of seven HMTs in 528 ccRCC, 288 pRCC and 66 chRCC samples, $\mathrm{P}<0.001$ in NSD1, $\mathrm{P}<0.001$ in PRDM6, $\mathrm{P}>0.05$ in other HMTs; $(\mathrm{B})$ homozygous deletion of two HMTs in 528 ccRCC, 288 pRCC and 66 chRCC samples, P<0.001 in SETD5, SETD2 and SETMAR; (C) mutation of two HMTs in 213 cCRCC, 113 pRCC and 65 chRCC specimens, $\mathrm{P}>0.05$ in $\mathrm{KMT} 2 \mathrm{C}$ and $\mathrm{P}=0.029$ in SETD2. 
A

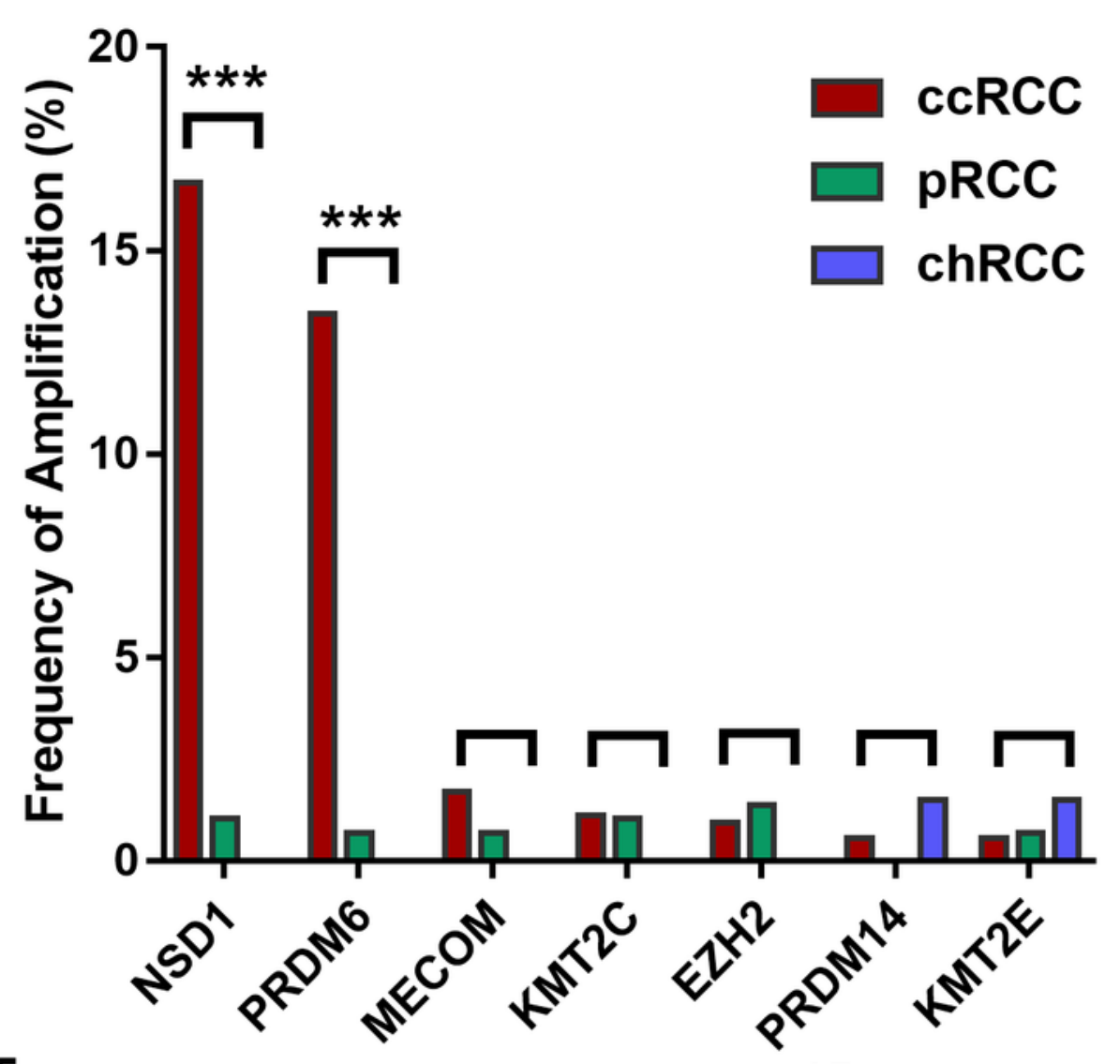

B

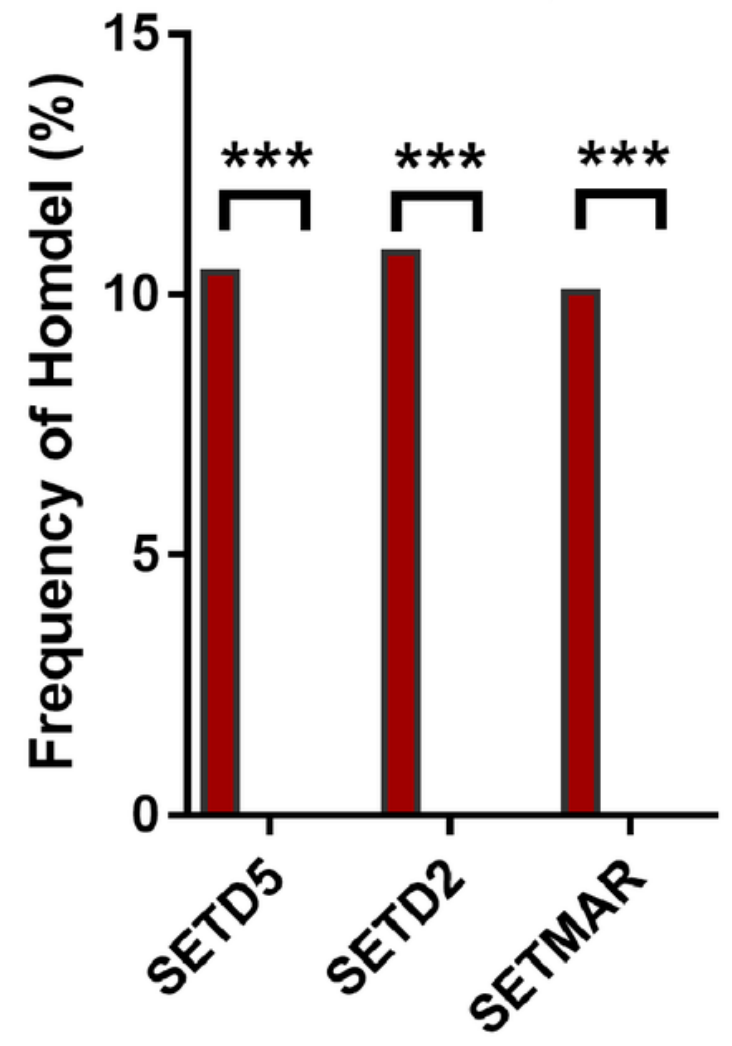

C

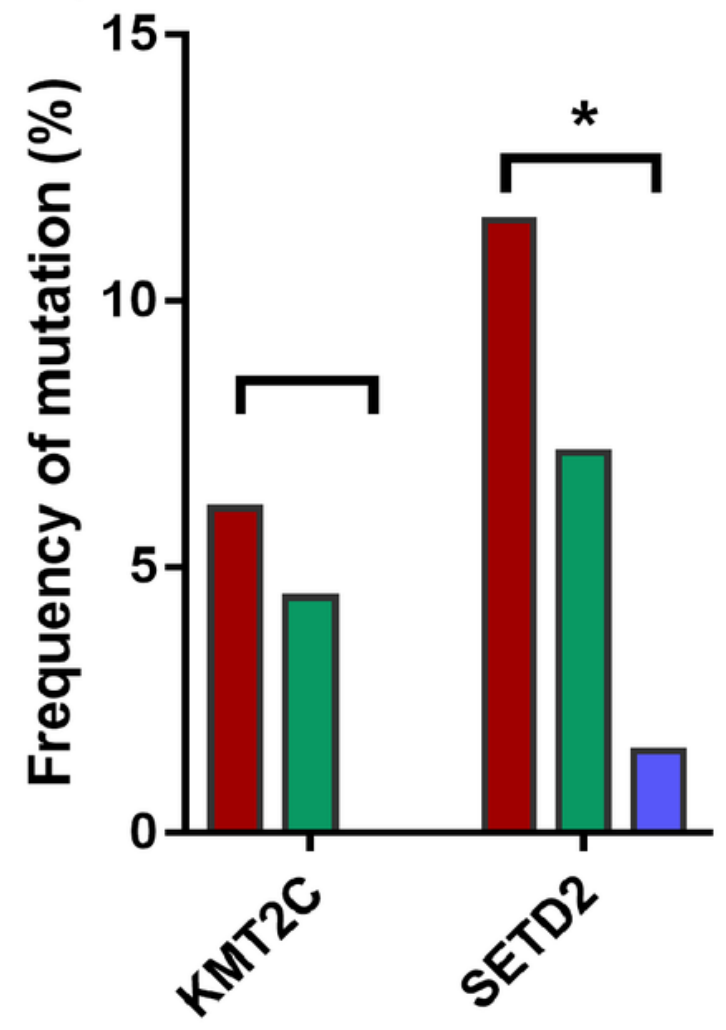




\section{Figure 2}

Heatmap of HMTs expression profiles in different types of renal cell carcinoma.

The kidney cancer samples used in this analysis included 66 chRCC, 288 pRCC, 528 ccRCC kidney cancer samples. Significantly higher-expressed genes $(p<0.001)$ in ccRCC tumors are shown at the top, indicated by a red box; and lower-expressed genes $(p<0.001)$ in ccRCC tumors are indicated by a blue box.

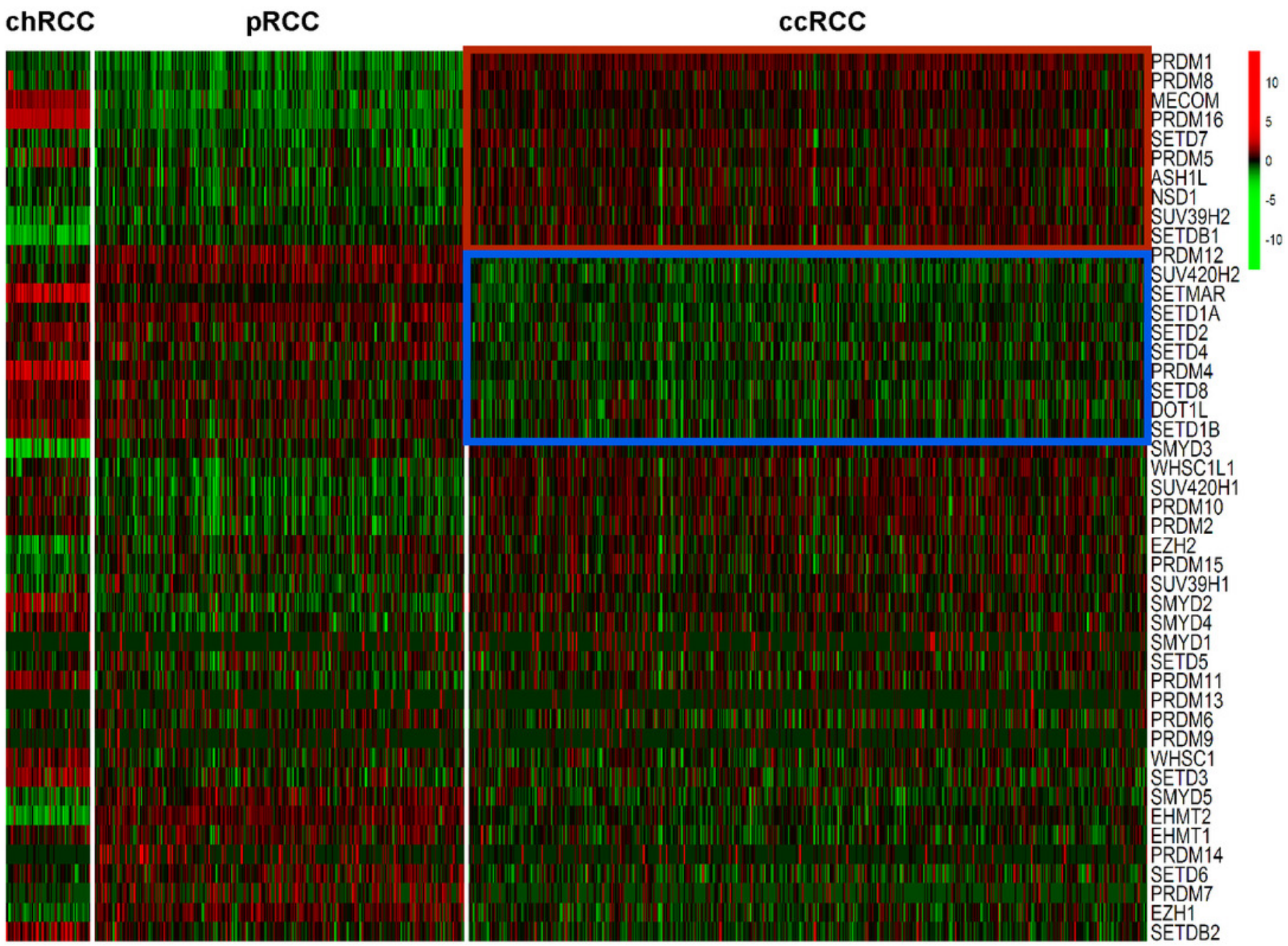




\section{Figure 3}

KMT2C and SETD2 mutational spectrum in renal cell carcinoma.

(A) Frequency of each mutation type for KMT2C and SETD2 from 213 renal cell carcinoma samples. The data were obtained from The Cancer Genome Atlas database via Cancer Browser. (B) The images show protein domains and the positions of specific mutations of KMT2C and SETD2. A red dot indicates a nonsense mutation, frameshift deletion, insertion, or splice; a green dot indicates a missense mutation; and a black dot indicates an inframe insertion or deletion. 
A

\begin{tabular}{lcc}
\hline Mutation Type & SETD2 & KMT2C \\
\hline Missense & 21 & 10 \\
Nonsense & 18 & 5 \\
Frameshift Deletion & 8 & 3 \\
Framshift Insertion & 5 & 0 \\
Splice & 6 & 2 \\
Other & 3 & 4 \\
\hline Total & 61 & 24
\end{tabular}

B KMT2C

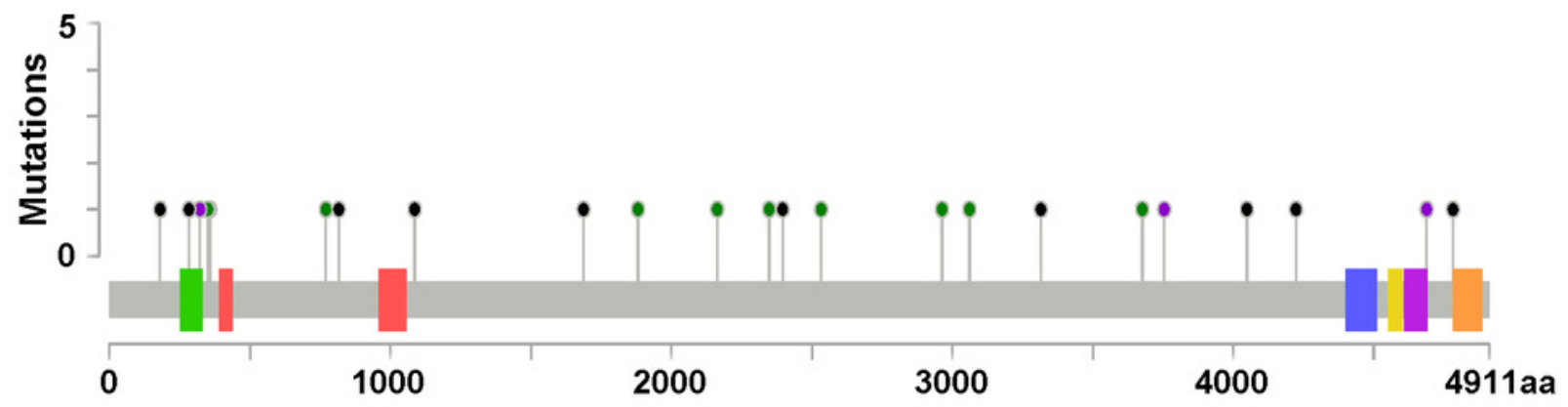

\section{SETD2}

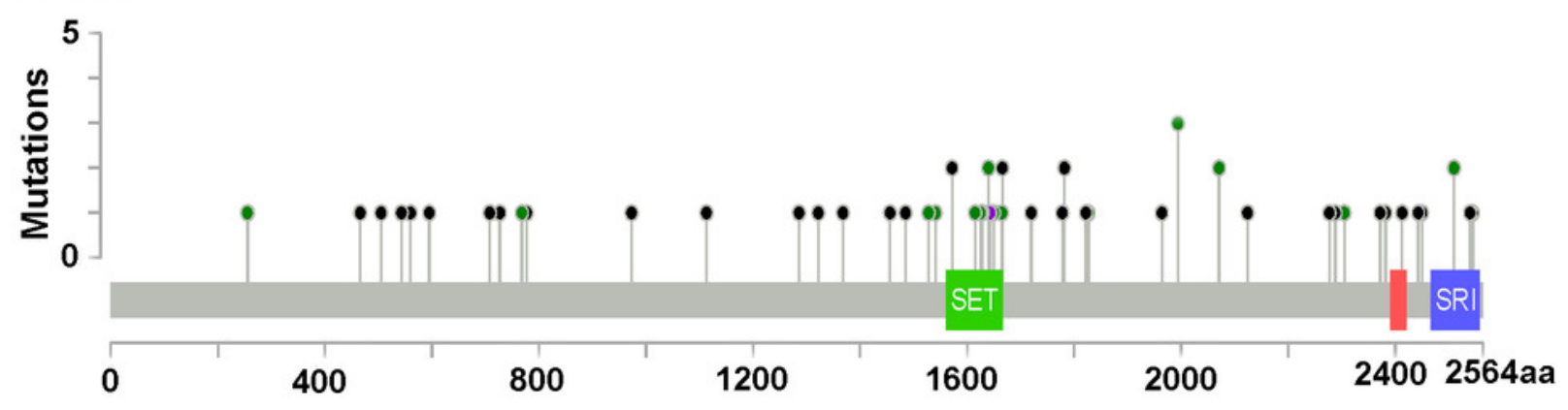


Figure 4

SET domain mutation VS non-SET domain mutation. ( Footnote: SET domain-M = SETD2 SET domain-mutation; SET domain-N = SETD2 non-SET domain mutation.) 


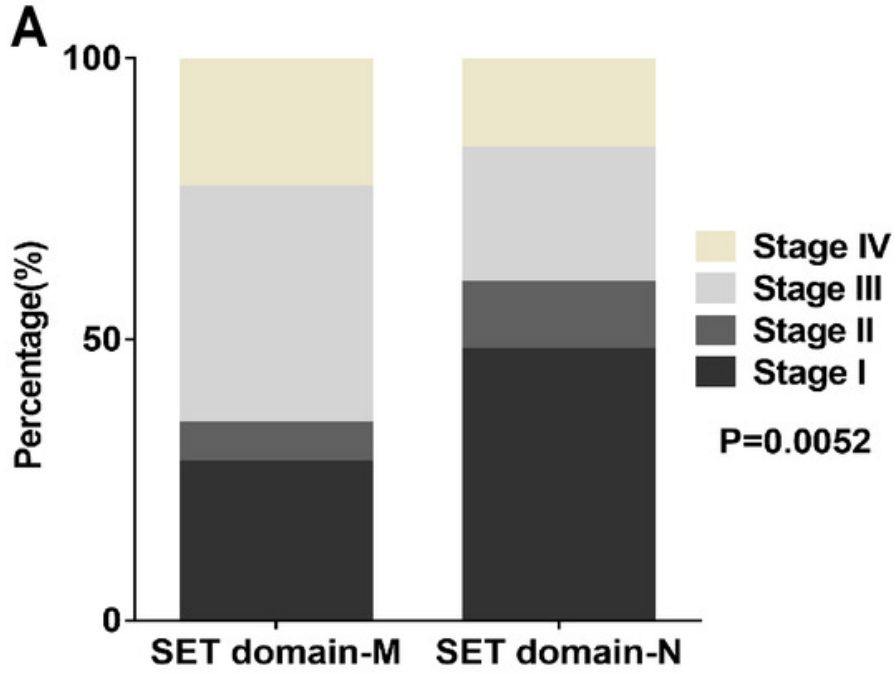

C Enrichment plot: HALLMARK_G2M_CHECKPOINT

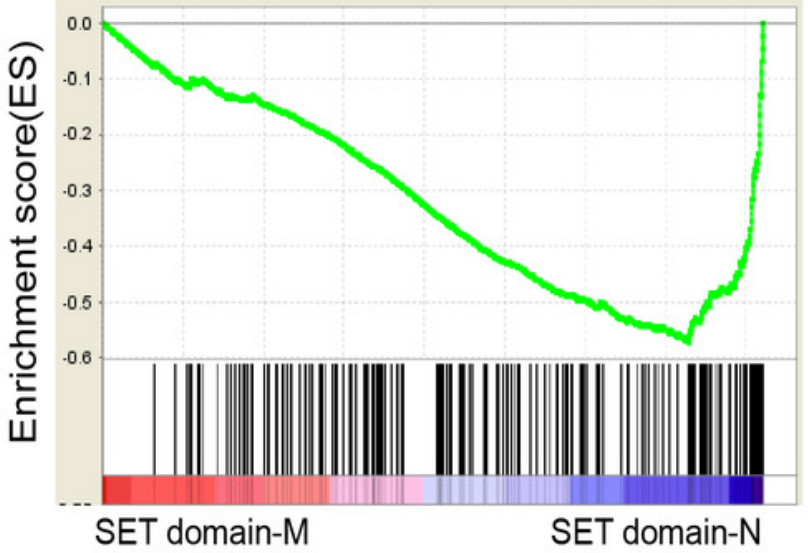

$\mathbf{E}$

\section{Enrichment plot: HALLMARK_E2F_TARGETS}

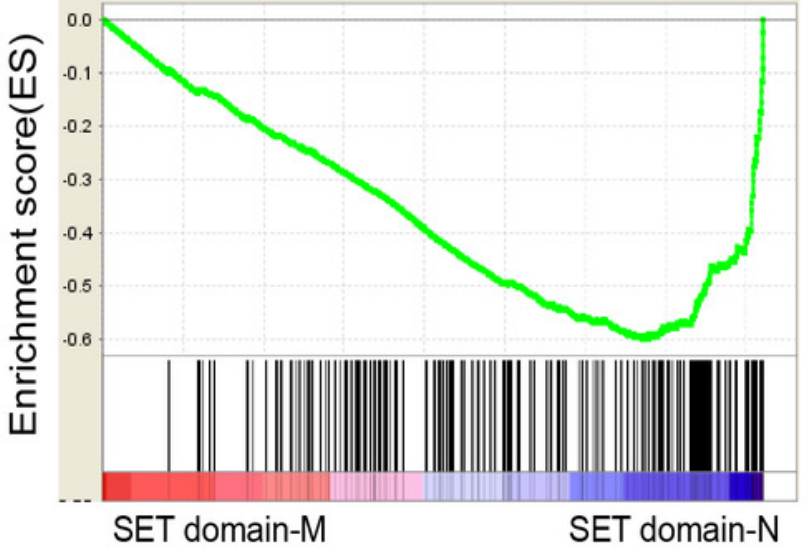

B

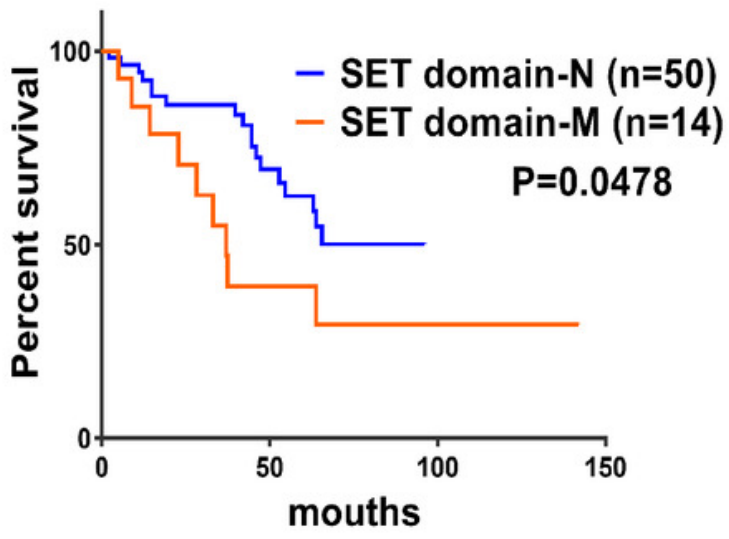

D

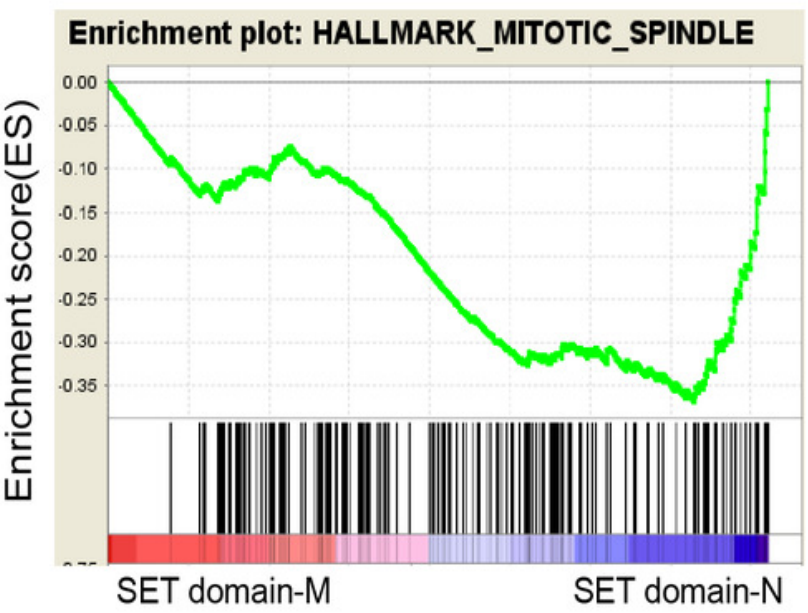

$\mathbf{F}$
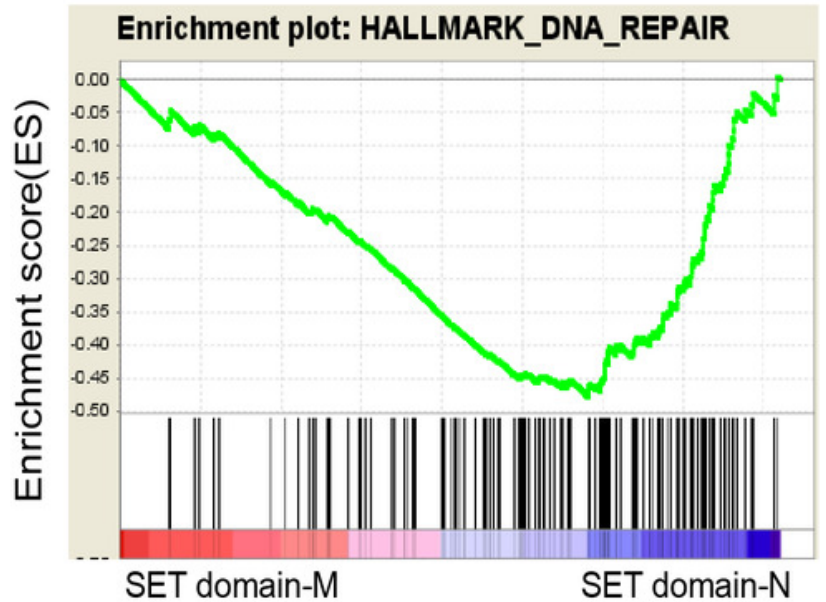
Figure 5

\section{Clinical outcome with CNA or gene expression level of HMTs.}

A

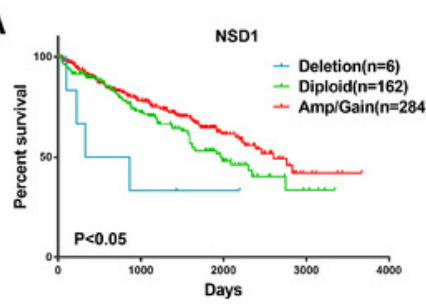

C

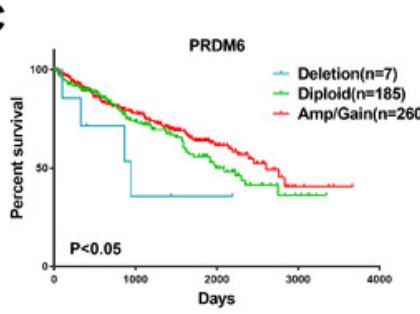

E

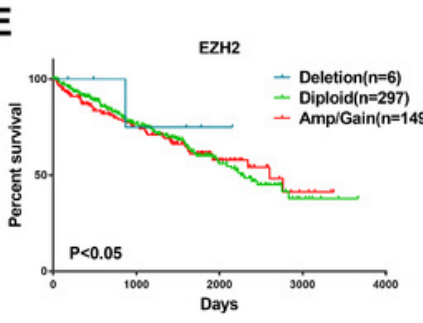

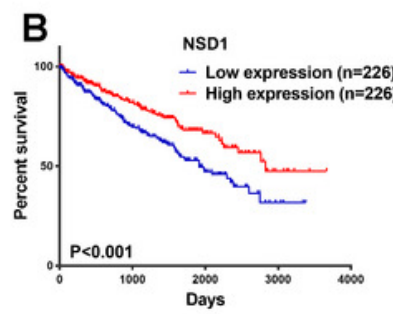

D
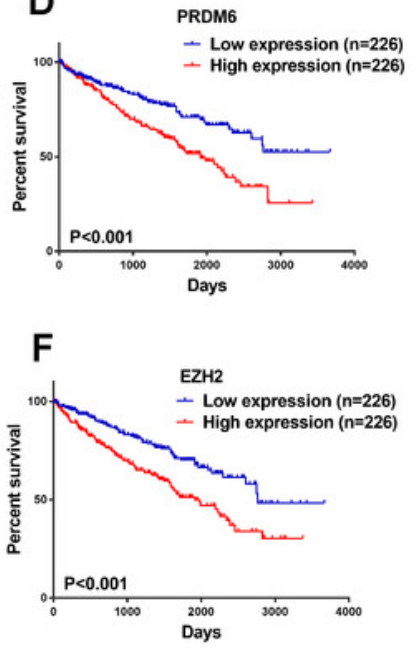

G

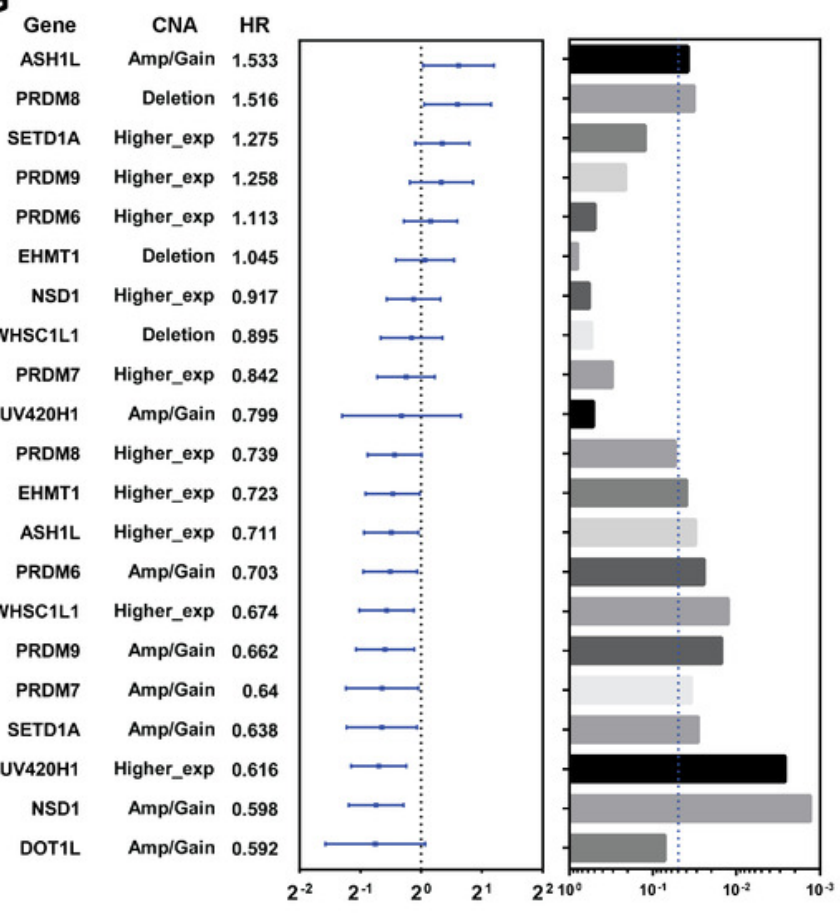


Figure 6

mRNA expression levels of eight HMTs in three RCC cell lines (OSRC-2, 786-O and ACHN) and renal tubular epithelial cell line (HK-2) measured by qRT-PCR.

mRNA relative expression level of 8 HMTs (NSD1, PRDM6, EZH2, WHSC1L1, SETD2, ASH1L, SETD1A and MECOM) in OSRC-2, ACHN, 786-O and HK-2 cell lines, the lowest gene expression level was set as " 1 " among the four cell lines. Relative expression levels are shown as fold changes compared with " 1 ".
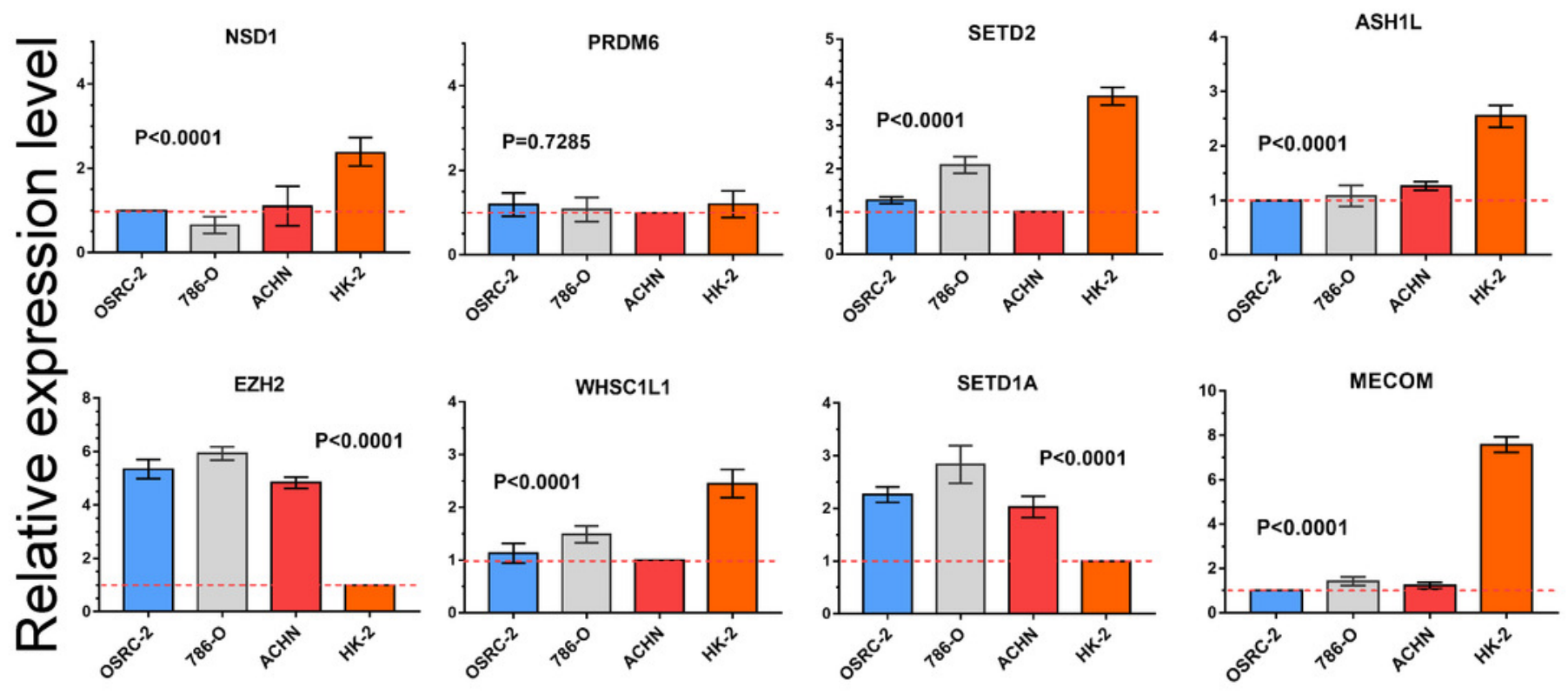
Figure 7

SETD2 inhibits cell proliferation in vitro.

(A) qPCR analysis of relative expression of SETD2 in sh-LacZ and sh - SETD2 cells. (B) MTS assays for 786-0 cells without or with stably SETD2 knockdown. (C, D) Migration and invasion analyses of Transwell for 786-O cells without or with stably SETD2 knockdown. (E, F) EdU assays for 786-0 cells without or with stably SETD2 knockdown. 
A

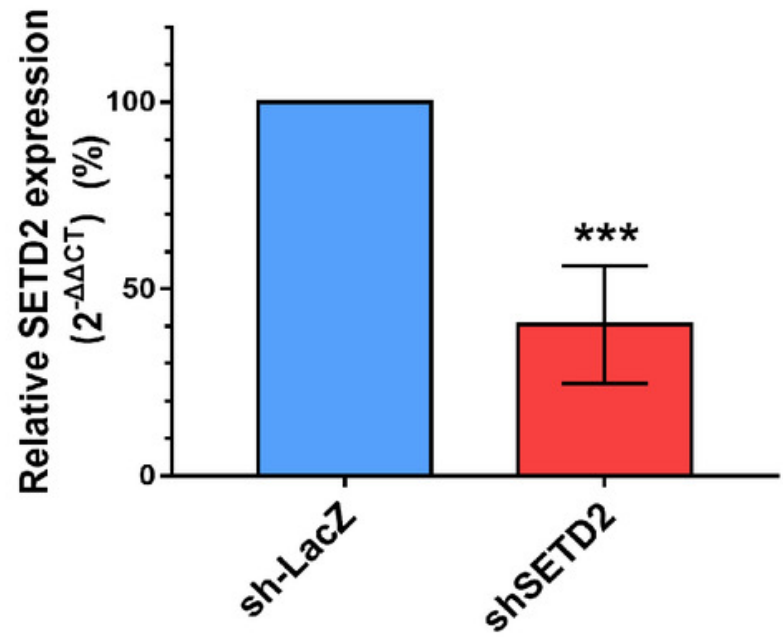

C sh-LacZ shSETD2

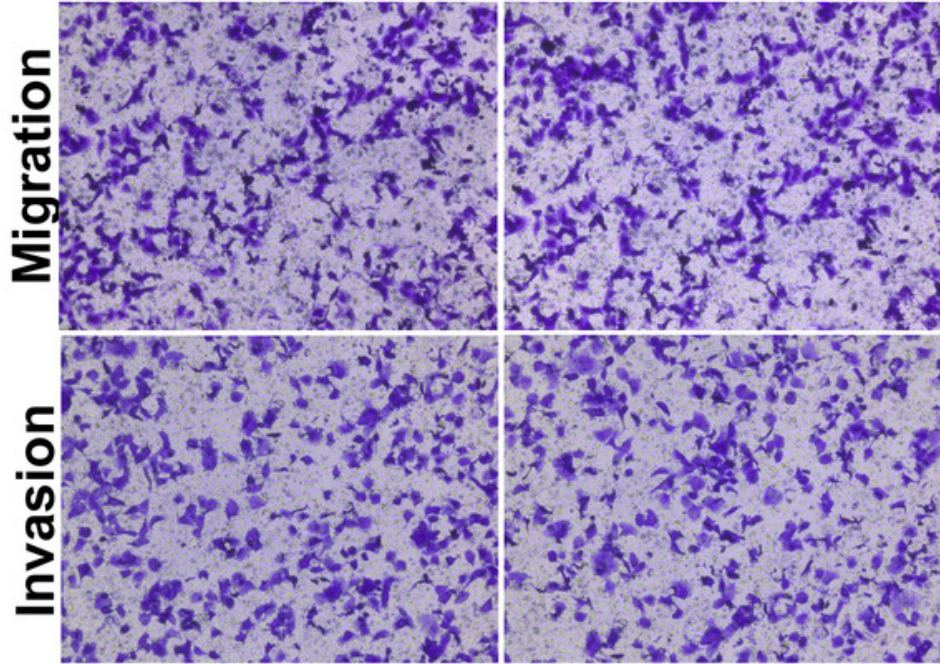

E
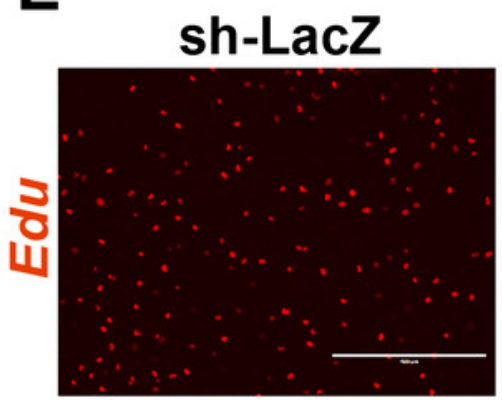

shSETD2

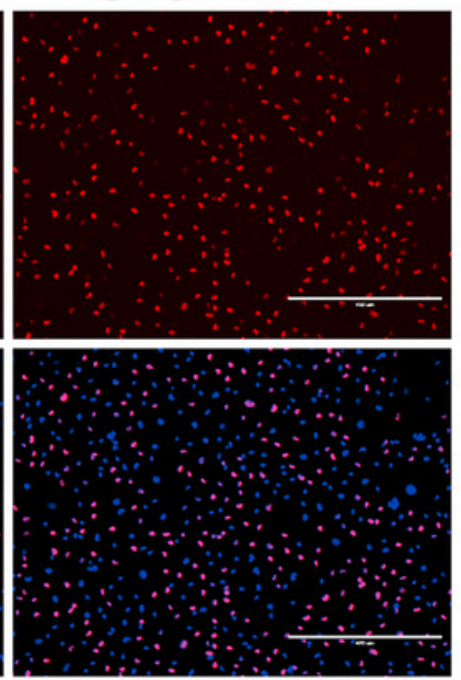

B

786-0

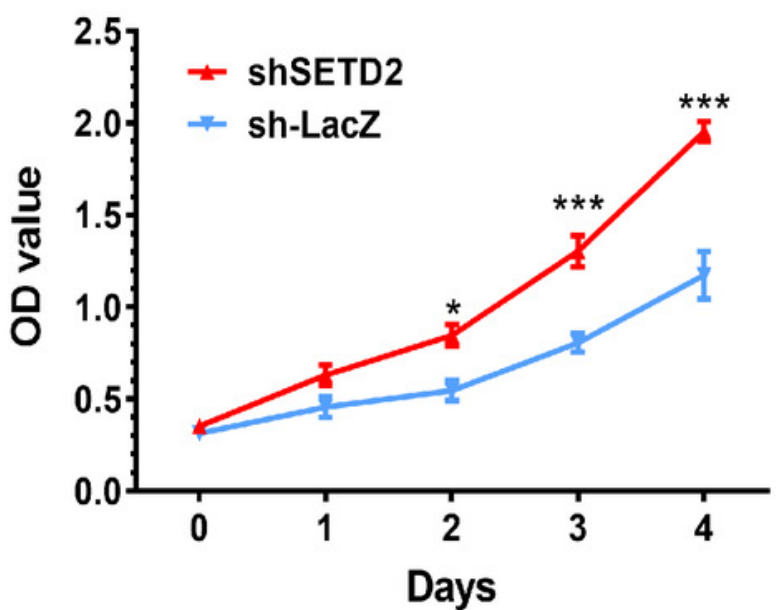

D

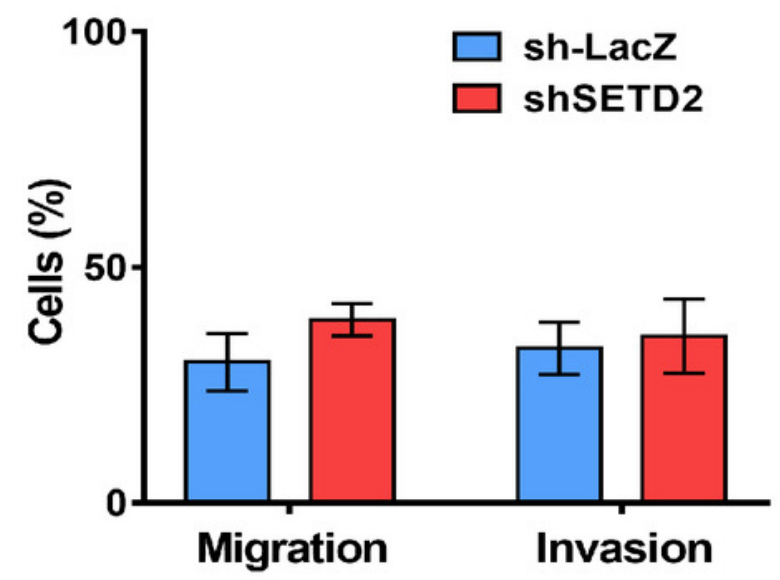

F

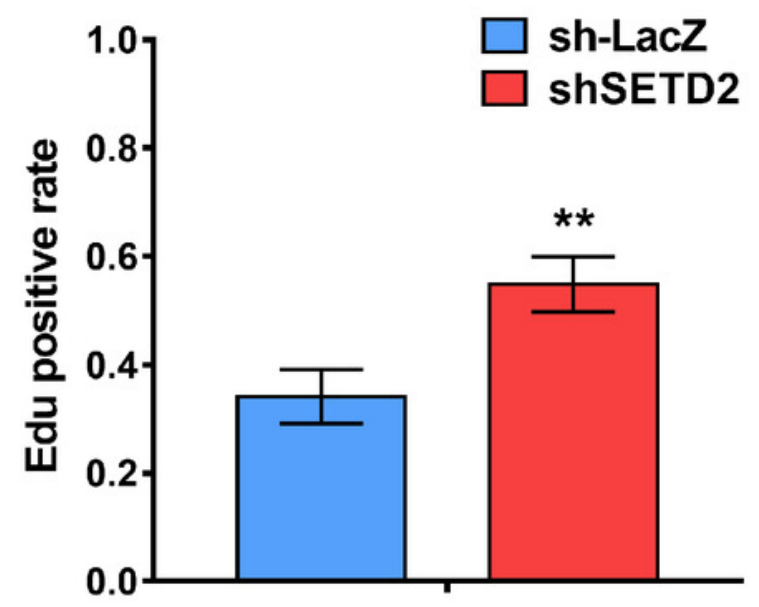




\section{Figure 8}

EZH2 promotes cell proliferation, migration and invasion in vitro.

(A) qPCR analysis of relative expression of EZH2 in sh-LacZ and sh - SETD2 cells. (B) MTS assays for 786-O cells without or with stably EZH2 knockdown. (C, D) Migration and invasion analyses of Transwell for 786-O cells without or with stably EZH2 knockdown. (E, F) EdU assays for 786-O cells without or with stably EZH2 knockdown. 
A

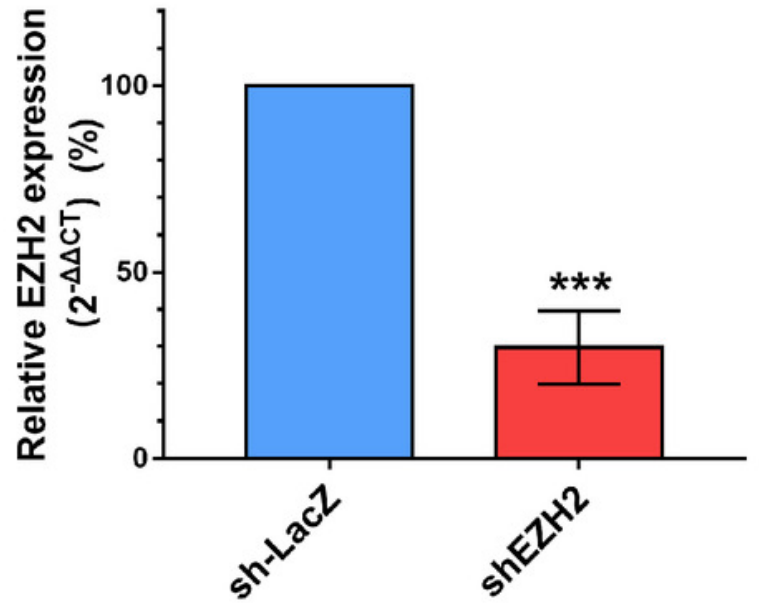

C
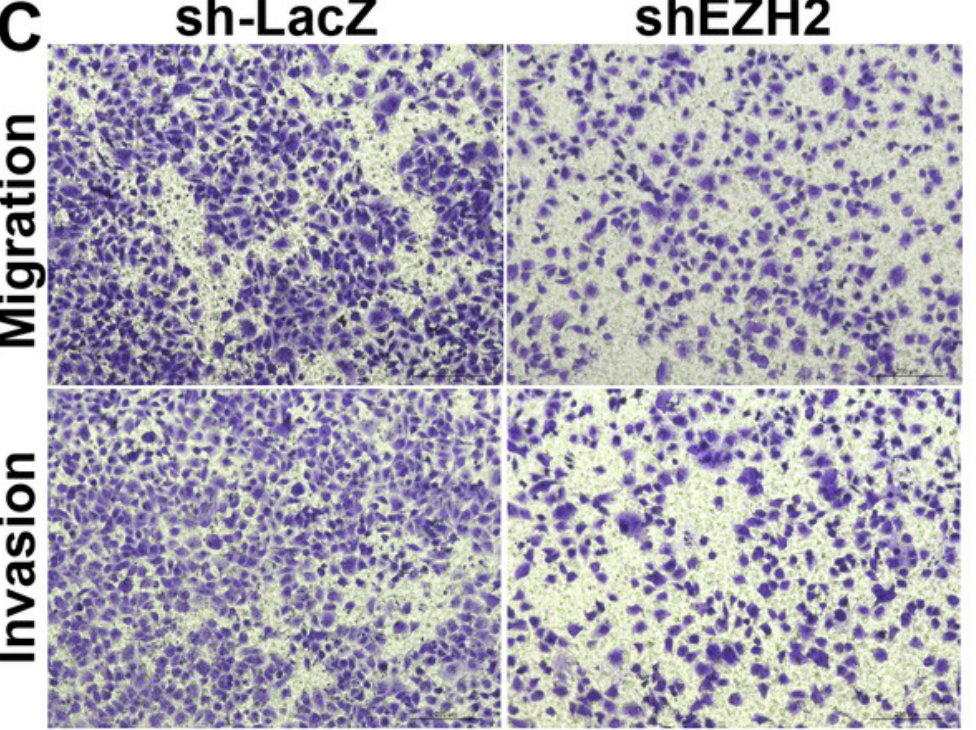

E
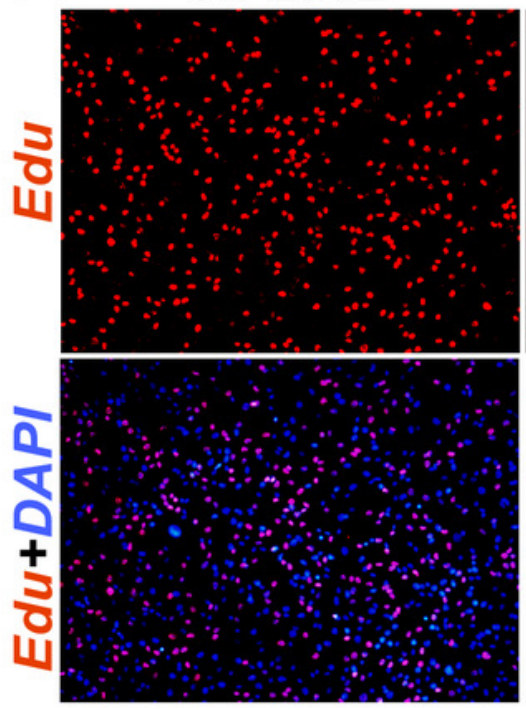

$786-0$

shEZH2

shEZH2

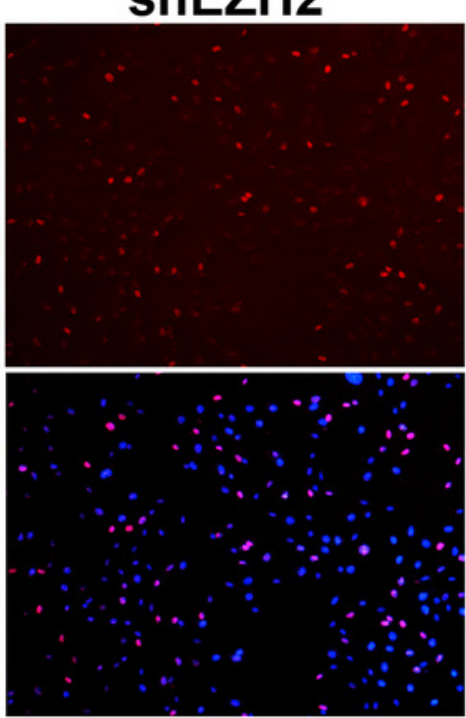

$786-0$
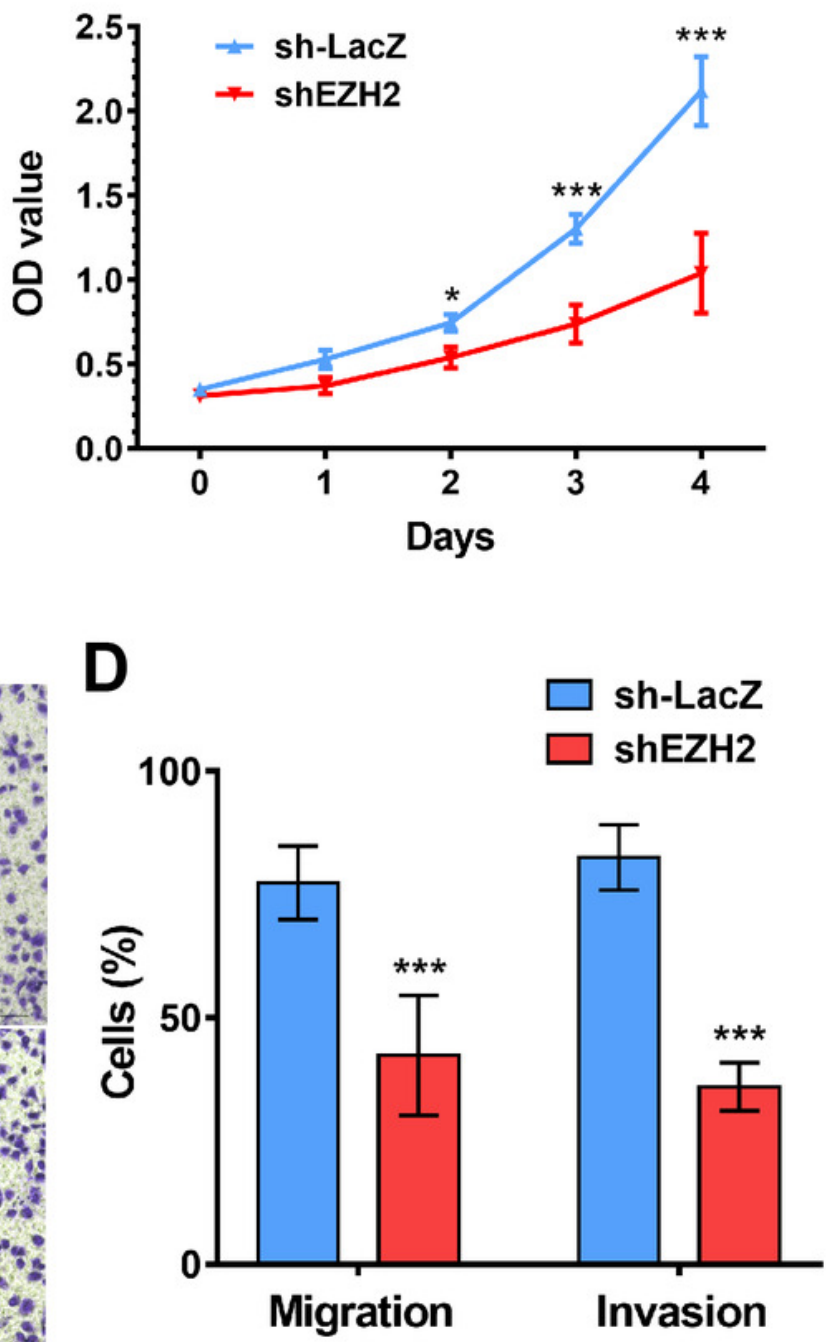

$\mathbf{F}$

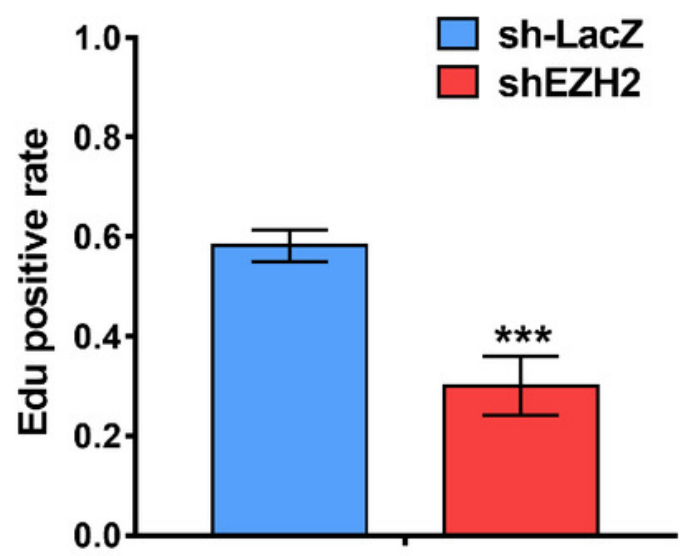




\section{Table $\mathbf{1}$ (on next page)}

Summary of identified human HMTs and their substrates 
Table 1: Summary of identified human HMTs and their substrates

\begin{tabular}{|c|c|c|c|c|}
\hline \multicolumn{5}{|l|}{ Official } \\
\hline Symbol & Other Aliases & Gene ID & Gene Location & Histone Substrates \\
\hline SUV42OH1 & CGI85; KMT5B & 51111 & $11 q 13.2$ & $\mathrm{H} 4 \mathrm{~K} 20$ \\
\hline SUV42OH2 & KMT5C & 84787 & $19 q 13.42$ & $\mathrm{H} 4 \mathrm{~K} 20$ \\
\hline ASH1L & ASH1; KMT2H; ASH1L1 & 55870 & $1 q 22$ & Н3К4; Н3К36 \\
\hline SMYD1 & KMT3D & 150572 & $2 \mathrm{p} 11.2$ & H3K4 \\
\hline SMYD3 & KMT3E; ZMYND1 & 64754 & $1 q 44$ & H3K4 \\
\hline SMYD2 & KMT3C; ZMYND14 & 56950 & $1 q 32.3$ & Н3К4; Н3К36 \\
\hline SMYD4 & ZMYND21 & 114826 & $17 p 13.3$ & \\
\hline SMYD5 & RRG1; RAI15 & 10322 & $2 \mathrm{p} 13.2$ & \\
\hline NSD1 & КМТЗВ & 64324 & $5 q 35.2$ & H3К36 \\
\hline WHSC1 & WHS; NSD2 & 7468 & $4 p 16.3$ & H3К36; H4K2O \\
\hline WHSC1L1 & NSD3; pp14328 & 54904 & $8 p 11.23$ & Н3К 4; Н3К27 \\
\hline DOT1L & DOT1; KMT4 & 84444 & $19 \mathrm{p} 13.3$ & H3K79 \\
\hline $\mathrm{EZH1}$ & KMT6B & 2145 & $17 q 21.2$ & H3K27 \\
\hline $\mathrm{EZH} 2$ & EZH1; KMT6 & 2146 & $7 q 36.1$ & H3K27 \\
\hline SETD3 & C14orf154 & 84193 & $14 q 32.2$ & \\
\hline SETD4 & C21orf18; C21orf27 & 54093 & $21 q 22.12$ & \\
\hline SETD6 & & 79918 & $16 q 21$ & \\
\hline SETD7 & KMT7; SET7; SET9 & 80854 & $4 q 31.1$ & H3K4 \\
\hline КМТ2B & MLL2; MLL4 & 9757 & $19 q 13.12$ & H3K4 \\
\hline КМT2C & HAIR; MLL3 & 58508 & $7 q 36.1$ & H3K4 \\
\hline КМT2A & HRX; MLL; MLL1 & 4297 & $11 q 23.3$ & H3K4 \\
\hline KMT2D & MLL2; MLL4 & 8085 & $12 q 13.12$ & H3K4 \\
\hline SETD8 & SET8; KMT5A; SETD7 & 387893 & $12 q 24.31$ & $\mathrm{H} 4 \mathrm{~K} 20$ \\
\hline MECOM & EVI1; PRDM3 & 2122 & $3 q 26.2$ & H3K9me1 \\
\hline PRDM16 & MEL1; LVNC8; PFM13 & 63976 & $1 p 36.32$ & H3K9me1 \\
\hline PRDM13 & PFM10 & 59336 & $6 q 16.2$ & \\
\hline PRDM8 & PFM5 & 56978 & $4 q 21.21$ & H3k9 \\
\hline PRDM1 & BLIMP1 & 639 & $6 q 21$ & \\
\hline PRDM2 & RIZ; KMT8 & 7799 & $1 p 36.21$ & H3k9 \\
\hline PRDM10 & PFM7 & 56980 & $11 q 24.3$ & \\
\hline PRDM12 & PFM9 & 59335 & $9 q 34.12$ & \\
\hline PRDM6 & & 93166 & $5 q 23.2$ & \\
\hline PRDM14 & PFM11 & 63978 & $8 q 13.3$ & \\
\hline PRDM4 & PFM1 & 11108 & $12 q 23.3$ & \\
\hline PRDM15 & PFM15; ZNF298 & 63977 & $21 q 22.3$ & \\
\hline PRDM5 & BCS2; PFM2 & 11107 & $4 q 27$ & \\
\hline PRDM7 & PFM4; ZNF910 & 11105 & $16 q 24.3$ & \\
\hline PRDM9 & PFM6; MSBP3; PRMD9 & 56979 & $5 p 14.2$ & H3K4 \\
\hline
\end{tabular}




\begin{tabular}{lllll} 
PRDM11 & PFM8 & 56981 & $11 \mathrm{p} 11.2$ & \\
EHMT1 & GLP; KMT1D & 79813 & $9 \mathrm{q} 34.3$ & H3K9; H1.2K187 \\
EHMT2 & G9A; NG36; KMT1C & 10919 & $6 \mathrm{p} 21.31$ & H3K9; H3K27 \\
SUV39H1 & MG44; KMT1A & 6839 & Xp11.23 & H3K9 \\
SUV39H2 & KMT1B & 79723 & $10 p 13$ & H3K9 \\
SETD1A & Set1; KMT2F; Set1A & 9739 & $16 p 11.2$ & H3K4 \\
SETD1B & KMT2G; Set1B & 23067 & $12 q 24.31$ & H3K4 \\
SETDB1 & ESET; KG1T; KMT1E & 9869 & $1 q 21.3$ & H3K9 \\
SETDB2 & CLLD8; CLLL8; KMT1F & 83852 & $13 q 14.2$ & H3K9 \\
SETD2 & SET2; HIF-1; HIP-1 & 29072 & $3 p 21.31$ & H3K36 \\
KMT2E & MLL5 & 55904 & $7 q 22.3$ & H3K4 \\
SETD5 & & 55209 & $3 p 25.3$ & \\
SETMAR & Mar1; HsMar1 & 6419 & $3 p 26.1$ & H3K36 \\
\hline
\end{tabular}

1 


\section{Table 2 (on next page)}

Frequency of HMT copy number alterations and mutations (\%)

Footnote: Amp=high-level amplification; Gain=low-level gain; Hetless=heterozygous deletion; Homdel=homozygous deletion. Genes were ranked based on the frequency of highlevel amplification. 
Table 2: Frequency of HMT copy number alterations and mutations (\%)

\begin{tabular}{|c|c|c|c|c|c|c|c|}
\hline Gene & Gene location & Amp & Gain & Diploid & Hetloss & Homdel & Mutation \\
\hline NSD1 & $5 q 35.2$ & 16.67 & 46.21 & 35.98 & 1.14 & 0.00 & 2.82 \\
\hline PRDM6 & $5 q 23.2$ & 13.45 & 44.13 & 41.10 & 1.33 & 0.00 & 0.00 \\
\hline MECOM & $3 q 26.2$ & 1.70 & 14.58 & 71.59 & 12.12 & 0.00 & 0.94 \\
\hline КMT2C & $7 q 36.1$ & 1.14 & 32.20 & 65.53 & 1.14 & 0.00 & 6.10 \\
\hline $\mathrm{EZH} 2$ & $7 q 36.1$ & 0.95 & 32.20 & 65.72 & 1.14 & 0.00 & 0.47 \\
\hline PRDM14 & $8 q 13.3$ & 0.57 & 12.12 & 74.43 & 12.88 & 0.00 & 0.47 \\
\hline KMT2E & $7 q 22.3$ & 0.57 & 32.58 & 66.67 & 0.19 & 0.00 & 1.41 \\
\hline SETDB1 & $1 q 21.3$ & 0.38 & 11.55 & 81.82 & 6.25 & 0.00 & 0.94 \\
\hline ASH1L & $1 q 22$ & 0.38 & 11.74 & 81.44 & 6.44 & 0.00 & 0.94 \\
\hline SETD1A & $16 p 11.2$ & 0.38 & 20.08 & 77.27 & 2.27 & 0.00 & 0.47 \\
\hline KMT2A & $11 q 23.3$ & 0.38 & 5.87 & 89.02 & 4.73 & 0.00 & 1.88 \\
\hline PRDM11 & $11 \mathrm{p} 11.2$ & 0.19 & 6.26 & 90.51 & 3.04 & 0.00 & 0.47 \\
\hline SMYD3 & $1 q 44$ & 0.19 & 10.80 & 81.06 & 7.95 & 0.00 & 0.00 \\
\hline WHSC1L1 & $8 p 11.23$ & 0.19 & 5.68 & 68.75 & 24.62 & 0.76 & 2.82 \\
\hline SMYD2 & $1 q 32.3$ & 0.19 & 10.98 & 81.25 & 7.58 & 0.00 & 0.47 \\
\hline PRDM1 & $6 q 21$ & 0.19 & 1.52 & 71.59 & 26.52 & 0.19 & 0.47 \\
\hline SUV39H2 & 10p13 & 0.19 & 3.22 & 84.09 & 12.31 & 0.19 & 0.00 \\
\hline PRDM9 & $5 p 14.2$ & 0.19 & 32.01 & 66.86 & 0.95 & 0.00 & 0.47 \\
\hline EZH1 & $17 q 21.2$ & 0.19 & 5.68 & 88.45 & 5.68 & 0.00 & 0.47 \\
\hline SUV39H1 & Xp11.23 & 0.19 & 5.49 & 85.42 & 8.52 & 0.38 & 0.00 \\
\hline PRDM7 & $16 q 24.3$ & 0.19 & 18.56 & 77.08 & 4.17 & 0.00 & 0.47 \\
\hline EHMT1 & $9 q 34.3$ & 0.19 & 2.84 & 67.61 & 28.98 & 0.38 & 0.94 \\
\hline PRDM10 & $11 q 24.3$ & 0.19 & 5.49 & 88.83 & 4.92 & 0.57 & 0.00 \\
\hline PRDM5 & $4 q 27$ & 0.19 & 2.08 & 83.33 & 14.20 & 0.19 & 0.47 \\
\hline DOT1L & $19 p 13.3$ & 0.19 & 8.71 & 87.50 & 3.22 & 0.38 & 0.94 \\
\hline SETD7 & $4 q 31.1$ & 0.19 & 2.65 & 82.95 & 14.02 & 0.19 & 0.00 \\
\hline SMYD4 & $17 p 13.3$ & 0.19 & 5.11 & 85.61 & 9.09 & 0.00 & 0.94 \\
\hline SETDB2 & $13 q 14.2$ & 0.19 & 3.98 & 80.49 & 15.15 & 0.19 & 0.00 \\
\hline SUV420H1 & $11 q 13.2$ & 0.00 & 6.25 & 90.15 & 3.60 & 0.00 & 1.41 \\
\hline SUV42OH2 & $11 q 13.2$ & 0.00 & 10.80 & 88.07 & 0.95 & 0.19 & 0.47 \\
\hline SETMAR & $3 p 26.1$ & 0.00 & 1.33 & 12.31 & 76.33 & 10.04 & 0.47 \\
\hline SETD5 & $3 p 25.3$ & 0.00 & 1.33 & 11.17 & 77.08 & 10.42 & 0.94 \\
\hline EHMT2 & $6 p 21.31$ & 0.00 & 1.89 & 79.17 & 18.94 & 0.00 & 1.41 \\
\hline PRDM13 & $6 q 16.2$ & 0.00 & 1.52 & 71.78 & 26.52 & 0.19 & 0.94 \\
\hline PRDM15 & $21 q 22.3$ & 0.00 & 9.66 & 79.55 & 10.42 & 0.38 & 0.47 \\
\hline PRDM16 & $1 p 36.32$ & 0.00 & 1.70 & 79.36 & 18.94 & 0.00 & 0.47 \\
\hline SETD4 & $21 q 22.12$ & 0.00 & 9.66 & 80.11 & 10.23 & 0.00 & 0.00 \\
\hline SETD8 & $12 q 24.31$ & 0.00 & 22.92 & 75.95 & 1.14 & 0.00 & 0.47 \\
\hline PRDM12 & $9 q 34.12$ & 0.00 & 2.46 & 68.37 & 28.98 & 0.19 & 0.00 \\
\hline
\end{tabular}




\begin{tabular}{llllllll} 
PRDM8 & $4 \mathrm{q} 21.21$ & 0.00 & 2.46 & 85.04 & 12.50 & 0.00 & 0.00 \\
SETD1B & $12 \mathrm{q} 24.31$ & 0.00 & 22.92 & 75.95 & 1.14 & 0.00 & 0.00 \\
SETD3 & $14 \mathrm{q} 32.2$ & 0.00 & 2.84 & 53.60 & 43.18 & 0.38 & 1.41 \\
WHSC1 & $4 \mathrm{p} 16.3$ & 0.00 & 2.84 & 83.90 & 13.26 & 0.00 & 1.88 \\
KMT2D & $12 \mathrm{q} 13.12$ & 0.00 & 22.73 & 76.33 & 0.95 & 0.00 & 1.41 \\
PRDM4 & $12 \mathrm{q} 23.3$ & 0.00 & 22.92 & 75.95 & 1.14 & 0.00 & 0.00 \\
SETD6 & $16 \mathrm{q} 21$ & 0.00 & 18.56 & 77.27 & 4.17 & 0.00 & 0.00 \\
SMYD5 & $2 \mathrm{p} 13.2$ & 0.00 & 14.39 & 82.95 & 2.65 & 0.00 & 0.00 \\
PRDM2 & $1 \mathrm{p} 36.21$ & 0.00 & 1.33 & 79.92 & 18.75 & 0.00 & 0.47 \\
SMYD1 & $2 \mathrm{p} 11.2$ & 0.00 & 14.39 & 83.14 & 2.46 & 0.00 & 0.00 \\
SETD2 & $3 \mathrm{p} 21.31$ & 0.00 & 1.14 & 10.80 & 77.27 & 10.80 & 11.51 \\
\hline
\end{tabular}

1 Footnote: Amp=high-level amplification; Gain=low-level gain; Hetless=heterozygous deletion; Homdel=homozygous 2 deletion. Genes were ranked based on the frequency of high-level amplification. 


\section{Table 3 (on next page)}

Associations between CNA and expression, and comparison of mRNA expression between $\mathrm{CCRCC}$ and non-ccRCC kidney cancer subtypes

Footnote: Genes were ranked based on the Spearman correlation coefficient. Significantly higher expression of HMTs in the cCRCC subtype is highlighted in dark gray, and sighificantly lower expression is highlighted in little gray. T statistics represents the T statistic, which is equivalent to the number of standard deviations of mRNA expression levels between the CCRCC and non-cCRCC subtypes. A positive value means that the CCRCC subtype has a higher value, and a negative value means that the ccRCC subtype has a lower value than the nonccRCC subtypes samples. 
Table3: Associations between CNA and expression, and comparison of mRNA expression between ccRCC and non-ccRCC kidney cancer subtypes

\begin{tabular}{|c|c|c|c|c|}
\hline \multirow[b]{2}{*}{ Gene } & \multicolumn{3}{|c|}{ CNA/mRNA Correlation } & \multirow{2}{*}{$\frac{\text { ccRCC /non-ccRCC Comparison }}{\text { T statistics }}$} \\
\hline & Spearman & Kendall & Pearson & \\
\hline WHSC1L1 & 0.689 & 0.596 & 0.669 & -0.09 \\
\hline SETDB1 & 0.580 & 0.509 & 0.597 & -0.02 \\
\hline NSD1 & 0.517 & 0.449 & 0.502 & -0.08 \\
\hline SMYD3 & 0.470 & 0.419 & 0.504 & -0.34 \\
\hline $\mathrm{EZH} 2$ & 0.462 & 0.414 & 0.459 & -0.07 \\
\hline SMYD2 & 0.433 & 0.392 & 0.427 & -0.14 \\
\hline SUV39H2 & 0.416 & 0.376 & 0.478 & -0.09 \\
\hline PRDM1 & 0.394 & 0.357 & 0.374 & -0.10 \\
\hline PRDM6 & 0.384 & 0.343 & 0.369 & 0.20 \\
\hline ASH1L & 0.380 & 0.345 & 0.389 & -0.08 \\
\hline SETD1A & 0.273 & 0.240 & 0.234 & 0.02 \\
\hline PRDM11 & 0.242 & 0.215 & 0.179 & -0.07 \\
\hline SMYD4 & 0.189 & 0.177 & 0.158 & -0.07 \\
\hline MECOM & 0.176 & 0.159 & 0.156 & -1.32 \\
\hline PRDM8 & 0.162 & 0.154 & 0.164 & -0.22 \\
\hline PRDM13 & 0.161 & 0.159 & 0.103 & -0.29 \\
\hline SMYD1 & 0.159 & 0.157 & 0.185 & 0.06 \\
\hline PRDM10 & 0.157 & 0.149 & 0.133 & -0.10 \\
\hline PRDM4 & 0.086 & 0.089 & 0.087 & -0.26 \\
\hline SUV420H1 & 0.087 & 0.091 & 0.085 & -0.15 \\
\hline SETD1B & 0.071 & 0.066 & 0.058 & -0.07 \\
\hline EHMT1 & 0.070 & 0.064 & 0.079 & 0.01 \\
\hline SETD8 & 0.068 & 0.063 & 0.058 & -0.02 \\
\hline SETD6 & 0.067 & 0.062 & 0.068 & 0.02 \\
\hline SETMAR & 0.063 & 0.058 & 0.043 & -0.23 \\
\hline EZH1 & 0.061 & 0.057 & 0.052 & -0.02 \\
\hline DOT1L & 0.060 & 0.056 & 0.049 & 0.15 \\
\hline SETD3 & 0.059 & 0.055 & 0.072 & -0.10 \\
\hline PRDM15 & 0.023 & 0.019 & 0.031 & 0.05 \\
\hline WHSC1 & 0.022 & 0.019 & 0.010 & -0.03 \\
\hline SETD5 & 0.021 & 0.018 & 0.008 & 0.00 \\
\hline PRDM7 & 0.020 & 0.018 & 0.015 & -0.11 \\
\hline PRDM14 & 0.018 & 0.016 & 0.023 & -0.31 \\
\hline SETDB2 & 0.016 & 0.014 & 0.021 & -0.08 \\
\hline PRDM5 & 0.011 & 0.009 & 0.003 & -0.58 \\
\hline PRDM12 & 0.010 & 0.009 & 0.001 & -0.32 \\
\hline PRDM9 & 0.009 & 0.009 & 0.002 & -0.32 \\
\hline
\end{tabular}




$\begin{array}{ccccc}\text { PRDM16 } & 0.008 & 0.007 & 0.048 & -1.50 \\ \text { PRDM2 } & 0.008 & 0.007 & 0.020 & -0.14 \\ \text { SUV39H1 } & 0.007 & 0.006 & 0.010 & -0.03 \\ \text { SETD4 } & 0.003 & 0.003 & 0.017 & -0.06 \\ \text { SETD2 } & 0.002 & 0.002 & 0.002 & 0.01 \\ \text { SETD7 } & 0.001 & 0.001 & 0.001 & -0.07 \\ \text { SMYD5 } & 0.001 & 0.000 & 0.029 & -0.06 \\ \text { EHMT2 } & 0.000 & 0.000 & 0.022 & -0.14\end{array}$

1 Footnote: Genes were ranked based on the Spearman correlation coefficient. Significantly higher expression of HMTs 2 in the cCRCC subtype is highlighted in dark gray, and sighificantly lower expression is highlighted in little gray. T 3 statistics represents the T statistic, which is equivalent to the number of standard deviations of mRNA expression levels 4 between the $\mathrm{CCRCC}$ and non-ccRCC subtypes. A positive value means that the ccRCC subtype has a higher value, 5 and a negative value means that the ccRCC subtype has a lower value than the non-ccRCC subtypes samples. 


\section{Table 4 (on next page)}

Integrative identification of critical HMTs in kidney cancer

Footnote: $\mathrm{CNA} /$ Mutation: amplifcation, deletion or mutation; $\mathrm{CNA} / \mathrm{mRNA}$ correlation: associations between CNA and gene expression; Expression: altered expression in RCC; mRNA/Survival: mRNA associated with patient survival; CNA/Survival: CNA associated with patient survival. 
Table 4 : Integrative identification of critical HMTs in kidney cancer

\begin{tabular}{|c|c|c|c|c|c|c|}
\hline Gene & CNA/Mutations & $\begin{array}{l}\text { CNA/mRNA } \\
\text { correlation }\end{array}$ & Expression & $\begin{array}{l}\text { mRNA/ } \\
\text { survial }\end{array}$ & $\begin{array}{c}\text { CNA/ } \\
\text { survival }\end{array}$ & Score \\
\hline ASH1L & + & & + & + & & 3 \\
\hline PRDM8 & + & & & & & 1 \\
\hline SETD1A & + & & + & & & 2 \\
\hline PRDM9 & + & & & & & 1 \\
\hline PRDM6 & + & & & + & + & 3 \\
\hline EHMT1 & + & & & & & 1 \\
\hline NSD1 & + & + & + & + & + & 5 \\
\hline WHSC1L1 & + & + & + & & & 3 \\
\hline PRDM7 & + & & & & & 1 \\
\hline SUV420H1 & + & & & + & & 2 \\
\hline DOT1L & + & & & & & 1 \\
\hline SETD2 & ++ & & + & + & & 4 \\
\hline $\mathrm{EZH} 2$ & + & & + & + & & 3 \\
\hline MECOM & + & & + & & & 2 \\
\hline SETD5 & + & & & + & & 2 \\
\hline SETMAR & + & & & + & & 2 \\
\hline KMT2C & ++ & & & & & 2 \\
\hline KMT2E & + & & & & & 1 \\
\hline
\end{tabular}

1 Footnote: CNA/Mutation: amplifcation, deletion or mutation; CNA/mRNA correlation: associations between CNA and

2 gene expression; Expression: altered expression in RCC; mRNA/Survival: mRNA associated with patient survival;

3 CNA/Survival: CNA associated with patient survival. 